\title{
Estimating tree height from TanDEM-X data at the northwestern Canadian treeline
}

\author{
Sofia Antonova ${ }^{\mathrm{a}, \mathrm{b}, *}$, Christian Thiel ${ }^{\mathrm{c}}$, Bernhard Höfle ${ }^{\mathrm{a}, \mathrm{d}}$, Katharina Anders ${ }^{\mathrm{a}}$, Veit Helm ${ }^{\mathrm{e}}$, \\ Simon Zwieback ${ }^{\mathrm{f}}$, Sabrina Marx ${ }^{\mathrm{a}}$, Julia Boike ${ }^{\mathrm{b}, \mathrm{g}}$ \\ a $3 D$ Geospatial Data Processing Group, Institute of Geography, Heidelberg University, Im Neuenheimer Feld 368, D-69120 Heidelberg, Germany \\ ${ }^{\mathrm{b}}$ Alfred Wegener Institute Helmholtz Center for Polar and Marine Research, Telegrafenberg A 45, 14473 Potsdam, Germany \\ ${ }^{c}$ DLR Institute for Data Science, Mälzerstraße 3, 07745 Jena, Germany \\ ${ }^{\mathrm{d}}$ Heidelberg Center for the Environment (HCE), c/o Institute of Environmental Physics, Im Neuenheimer Feld 229, 69120 Heidelberg, Germany \\ ${ }^{\mathrm{e}}$ Alfred Wegener Institute Helmholtz Center for Polar and Marine Research, Postfach 1201 61, 27515 Bremerhaven, Germany \\ ${ }^{\mathrm{f}}$ Geophysical Institute, University of Alaska Fairbanks, Fairbanks, AK 99775, USA \\ ${ }^{\mathrm{g}}$ Department of Geography, Humboldt University of Berlin, Unter den Linden 6, 10099 Berlin, Germany
}

\section{A R T I C L E I N F O}

Edited by Emilio Chuvieco

Keywords:

Bistatic

CossC

Backscatter

Coherence

Interferometry

InSAR height

Forest patches

LiDAR

ALS

\begin{abstract}
A B S T R A C T
The circum-Arctic transitional zone between forest and tundra, i.e. the treeline zone, is shifting northward due to current Arctic warming and, therefore, requires systematic monitoring. Up to now, radar remote sensing was hardly possible in the treeline zone due to spatial resolution and/or temporal decorrelation constraints of preceding satellite missions. The unique constellation of the TanDEM-X satellites with its bistatic mode and very high spatial resolution opens up opportunities for monitoring small $\left(\geq 0.01 \mathrm{~km}^{2}\right)$ and isolated patches of very sparse forest which are typical for the transitional zone. We focused on an area at the northern edge of the treeline zone in the Northwest Territories, Canada, and evaluated the potential of TanDEM-X bistatic data to characterize the tree height in the forest patches in this region. TanDEM-X data were acquired during the TanDEM-X Science Phase in 2015, when the perpendicular baseline was large (corresponding to the height of ambiguity of approximately $14.6 \mathrm{~m}$ ) and kept constant. We employed TanDEM-X backscatter, bistatic coherence, and interferometric height from the stack of seven multitemporal bistatic pairs and compared them to maximum vegetation height obtained from full-waveform airborne LiDAR data. We found strong linear relationships between all TanDEM-X metrics and LiDAR vegetation height within the forest patches with $r=0.67, r=-0.69$, and $r=0.78$ for the backscatter, coherence, and interferometric height, respectively. Furthermore, we extracted the position of individual trees from the LiDAR data and estimated tree density as the number of trees per unit area. The linear relationships between all TanDEM-X metrics and the tree density were very weak. The relationships between all TanDEM-X metrics and tree height differentiated for three tree density classes (low, medium, and high) remained strong. Random forests regression using all three TanDEM-X metrics predicted the tree height with a mean absolute error of $0.7 \mathrm{~m}$ (mean forest height in the study area was $2.5 \mathrm{~m}$ ). CoSSC pairs were generally consistent with each other and the multitemporal averaging slightly improved the performance compared to single pairs. Taking into account the global coverage of bistatic TanDEM-X data acquired for the global digital elevation model, our results show a potential for quantifying the tree height in small forest patches along the circum-Arctic treeline zone.
\end{abstract}

\section{Introduction}

The circum-Arctic treeline (or forest-tundra transition zone) is the longest vegetation transition zone on Earth; it extends for $>13,400 \mathrm{~km}$ around the North American and Eurasian continents. The position of the treeline has shifted northward in the past in response to a warming climate, e.g. during the Holocene Climate Optimum (e.g. MacDonald et al., 1993). The current Arctic warming is expected to result in a northward advance of the treeline by $>500 \mathrm{~km}$ during the 21st century (Callaghan et al., 2005) as trees and shrubs encroach on the tundra

\footnotetext{
* Corresponding author at: Alfred Wegener Institute, Telegrafenberg A 45, 14473 Potsdam, Germany.

E-mail addresses: sofia.antonova@awi.de (S. Antonova), christian.thiel@dlr.de (C. Thiel), hoefle@uni-heidelberg.de (B. Höfle), katharina.anders@uni-heidelberg.de (K. Anders), veit.helm@awi.de (V.Helm), szwieback@alaska.edu (S. Zwieback), marx@uni-heidelberg.de (S. Marx), julia.boike@awi.de (J. Boike).
} 
(Chapin III et al., 2005). An advancing treeline has already been reported from numerous sites in the circum-Arctic treeline zone (e.g. Harsch et al., 2009; Frost and Epstein, 2014). The expansion of the boreal forest into tundra areas might cause vegetation climate feedback through radiation balance and snow cover changes (Chapin III et al., 2005). Furthermore, the carbon budget is changed through increase of carbon storage above ground with woodier biomass, as well as below ground through changes in litter quality and production.

However, some studies also report no changes or even a retreat of the treeline at some sites. Besides the spatial migration, treeline dynamics can also manifest in changes of vegetation structural properties, i.e. height and density. It is recognized that the treeline dynamics depend on a range of local conditions (e.g. Frost and Epstein, 2014). For instance, moisture availability can be affected either by increased drainage or by excessive melt water due to permafrost thaw (Lawrence et al., 2015). Furthermore, a decades-to-centuries delay of treeline response to climatic changes is possible due to seed dispersal limitations and generally slow reproduction rates at high latitudes (e.g. Lenoir and Svenning, 2015; Wieczorek et al., 2017). It is, therefore, essential to monitor the changes in vegetation properties in the treeline zone and the factors influencing these changes. One of the spatial forms represented in the treeline zone is a forest patch, where a group of trees grow in similar environmental conditions. Montesano et al. (2016) suggest that the accurate estimation of tree height in such forest patches is crucial for monitoring treeline changes and that improving the remote sensing of this parameter is a high priority.

Remote sensing of the Arctic treeline has generally been limited to optical sensors which vary in spatial resolution from the MODIS $(500 \mathrm{~m})$ to the Landsat $(30 \mathrm{~m})$ and high-resolution satellite and airborne imagery (few meters to sub-meter resolution) (e.g. Montesano et al., 2009; Ranson et al., 2011; Mathisen et al., 2014). Sensors with coarse resolution often cannot detect sparse forest at the northern edge of the treeline. Moreover, optical imagery is highly affected by clouds and generally insensitive to the vertical structure of vegetation. In contrast, Synthetic Aperture Radar (SAR) remote sensing is unconstrained by weather and light conditions, and can penetrate through a vegetation layer to a depth that depends on the radar wavelength. The latter property enables the SAR signal to be related to the structural characteristics of the vegetation, making SAR extremely useful in boreal, temperate, tropical and sub-tropical forest studies (e.g. Santoro and Cartus, 2018). The vegetation characteristics (i.e. biomass) can be estimated via backscatter, which represents the amplitude from a single SAR image, or via interferometry (InSAR) which is based on a complex product of two SAR images acquired from different positions in space and/or at different points in time. Therein, the phase differences between the two SAR images (InSAR phase) can refer to the vertical position of the scattering center in the case of no elevation change between acquisitions. An InSAR height, which can be attributed to the vegetation height, can then be obtained by subtracting the bare ground topography phase, i.e. the ground surface without elevated objects, from the InSAR phase. The magnitude of the complex product - InSAR correlation or coherence - indicates the stability of the phase and mostly refers to the physical distribution of the scatterers in a volume (volumetric component of coherence) and/or physical change of the scatterers between acquisitions (temporal component of coherence). By minimizing the temporal component of decorrelation, it is possible to relate the total coherence to the vegetation structural properties. InSAR techniques are widely used for estimating the biomass of boreal and tropical forests (e.g. Treuhaft et al., 2015; Schlund et al., 2016; Thiel and Schmullius, 2016). However, SAR interferometry has been unable, thus far, to focus on the treeline, mainly due to spatial resolution and/ or temporal decorrelation constraints of most satellite constellations. SAR backscatter from medium-resolution sensors ( $\sim 25 \mathrm{~m}$ pixel size) was employed in few studies on the treeline but only as a source of additional information together with optical sensors (Ranson et al., 2004) and/or airborne Light Detection And Ranging (LiDAR) data
(Montesano et al., 2016).

The bistatic SAR mode typically employs two satellites flying close to each other; one of the satellites transmits the signal, and both satellites receive the echo simultaneously. Such a mode removes most of the temporal component of decorrelation and, therefore, the coherence can be almost solely attributed to the scattering volume, determined by vegetation properties. TanDEM-X (TerraSAR-X add-on for Digital Elevation Measurement), operated by the German Aerospace Center (DLR), is the first operational spaceborne bistatic SAR system (Krieger et al., 2007). It consists of two nearly identical X-band satellites TerraSAR-X and TanDEM-X. The constellation began global acquisition in December 2010 with the primary goal of generating a global high-resolution and high-precision Digital Elevation Model (DEM). The high potential of interferometric TanDEM-X data acquired for the global DEM was already shown in the estimation of tree height and biomass in the boreal (e.g. Askne et al., 2013; Solberg et al., 2013; Karila et al., 2015; Soja et al., 2015; Persson et al., 2017; Sadeghi et al., 2018) and tropical (e.g. Treuhaft et al., 2015; Solberg et al., 2017) forests. Furthermore, Persson and Fransson (2017) and Sadeghi et al. (2016) show the feasibility of TanDEM-X to replace airborne LiDAR data for the biomass estimation in Swedish and Canadian boreal forest. Such feasibility is essential due to a limited availability of LiDAR data on large scale. The Arctic treeline lacks LiDAR and field observations especially strong. TanDEM-X data with their ground resolution, unprecedented for radar, provide unique opportunities for its accurate investigation.

This study is the first to evaluate the potential of TanDEM-X data for estimating tree height in small forest patches in the Canadian Arctic. In particular, we test the performance of TanDEM-X backscatter, bistatic coherence, and InSAR height from several TanDEM-X bistatic pairs obtained with the same geometry and baseline during the TanDEM-X Science Phase. As a reference, we use full-waveform Airborne Laser Scanning (ALS) data. We investigate the relationship between three TanDEM-X variables and ALS-based forest height, and, additionally, the effect of tree density (i.e. number of trees per unit area) on these relationships. Furthermore, we investigate the temporal consistency of the TanDEM-X pairs with respect to the potential weather influence.

\section{Study area}

The study area covers the Trail Valley Creek research basin $\left(68^{\circ} 44^{\prime} 17^{\prime \prime} \mathrm{N} ; 133^{\circ} 26^{\prime} 26^{\prime \prime} \mathrm{W}\right)$, which is located about $50 \mathrm{~km}$ northeast of Inuvik, Northwest Territories, Canada (Fig. 1). Research has been conducted in this basin is subject to research since 1991 with a focus on snow, permafrost, and hydrology. The area is characterized by gentle topography with prominently incised river valleys. It belongs to the continuous permafrost zone, with permafrost thicknesses up to $100 \mathrm{~m}$ and very high ground ice content (Burn and Kokelj, 2009). The climate features long and cold winters and short and cool summers, with mean annual temperature of $-7.3^{\circ} \mathrm{C}$, mean February temperature of $-22.8^{\circ} \mathrm{C}$ (the coldest month), and mean July temperature of $12.9^{\circ} \mathrm{C}$ (the warmest month) over the last decade (Environment and Climate Change Canada, 2019). Snowmelt typically occurs during May and June (Marsh et al., 2002). The region is experiencing rapid climate change. Serreze et al. (2000) report an increase in mean annual air temperature at all meteorological stations in Yukon and the Northwest Territories for two 30-year periods, from 1951 to 1980 and from 1971 to 2000. Burn and Kokelj (2009) analyzed air temperatures in Inuvik and observed an increase of the annual mean temperature by $>2.5^{\circ} \mathrm{C}$ since 1970. Following the rise of air temperature, the ground temperature also increased by approximately $1.6^{\circ} \mathrm{C}$. Ecologically, the area is located at the northern edge of the treeline zone. According to Marsh et al. (2010), the land cover consists of tundra (lichen, mosses, herbs, and low shrubs $<0.5 \mathrm{~m}$ in height), shrub tundra (deciduous shrubs from 0.5 to $3.0 \mathrm{~m}$ in height), and sparse forest with black spruce trees ( $>3.0 \mathrm{~m}$ in height) (Fig. 2). Shrub expansion, reported from many Arctic sites, was also observed in this region (e.g. Lantz et al., 2010). 


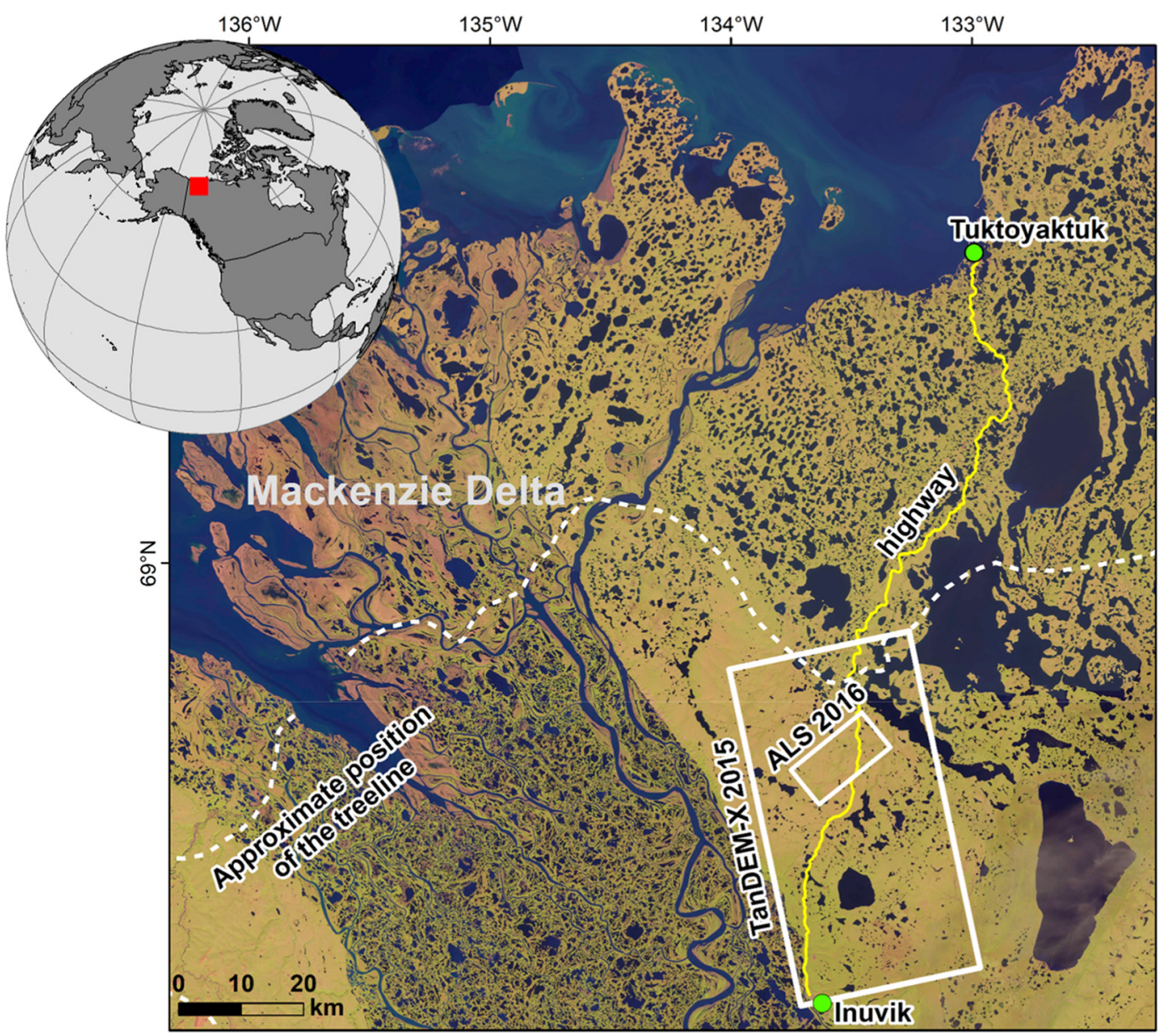

Fig. 1. Study area near the Mackenzie Delta, Northwest Territories, Canada. Geographical extents of TanDEM-X and ALS datasets are shown as white rectangles, the Inuvik-Tuktoyaktuk highway is shown with a solid yellow line, and the approximate position of the treeline (Brown et al., 1998) is shown with a dashed white line. Underlying image is the mosaic of true color Landsat-8 images from 2015 to 2016 (images are courtesy of the U.S. Geological Survey). The inset map at the top left shows the location of the study area in North America. (For interpretation of the references to color in this figure legend, the reader is referred to the web version of this article.)

\section{Data}

\subsection{ALS data}

Full-waveform 3D point cloud data were captured with a Riegl LMSQ680i airborne laser scanner on board the Alfred Wegener Institute's Polar 5 research aircraft. The survey took place in September 2016 and covered an area of about $20 \mathrm{~km} \times 6 \mathrm{~km}$ (cf. Fig. 1). The point density was approximately 5 points per square meter. The ALS point cloud with detailed description is published in PANGAEA and open for further use (Anders et al., 2018).

\subsection{TanDEM-X data}

During the TanDEM-X Science Phase (15 months during 2014-2015), special configurations of satellites and imaging modes were set up to perform various scientific experiments, including monitoring of vegetation (Hajnsek et al., 2014). Within the Science Phase, acquisitions with a long and extremely stable perpendicular baseline were available in summer 2015 for our research area. We used seven co-registered single look slant range complex (CoSSC) pairs acquired in the StripMap mode from 1 June to 28 August 2015. Table 1 lists the main parameters of the TanDEM-X dataset.

Height of ambiguity (HoA) is related to the perpendicular baseline and shows the sensitivity of InSAR phase to the height. If an object is lower than the HoA, the InSAR height can be unambiguously retrieved. If an objects is higher than the HoA, the phase unwrapping, i.e. finding a correct multiplier to the $2 \pi$ phase change, can introduce errors that potentially impede the data examination. The effective baseline (half the length of the perpendicular baseline for the TanDEM-X bistatic products) and HoA for the dataset used in this study are given in Table 2. For all acquisitions, baselines were kept extremely stable, with a maximum difference of $1.5 \mathrm{~m}$. This provides an opportunity to combine acquisitions without accounting for differences in geometry. The weather conditions were taken from the Environment and Climate Change Canada (2019) and are given in Table 2. Negative air temperature was observed at the time of the 1 June 2015 acquisition. Precipitation of $8.4 \mathrm{~mm}$ was recorded on 6 August 2015.

\section{Methods}

\subsection{Derivation of DTM and vegetation properties from ALS}

A Digital Terrain Model (DTM) was derived from the ALS point cloud in two main steps. In the first step, points were classified as terrain based on a probability value derived from the relationship between the echo width and amplitude values of each laser return (Mücke et al., 2010). These terrain points were rasterized into the DTM with a cell size of $1 \mathrm{~m}$ using a moving planes interpolation strategy (Pfeifer and Mandlburger, 2008) and then resampled to a cell size of $10 \mathrm{~m}$ to match 

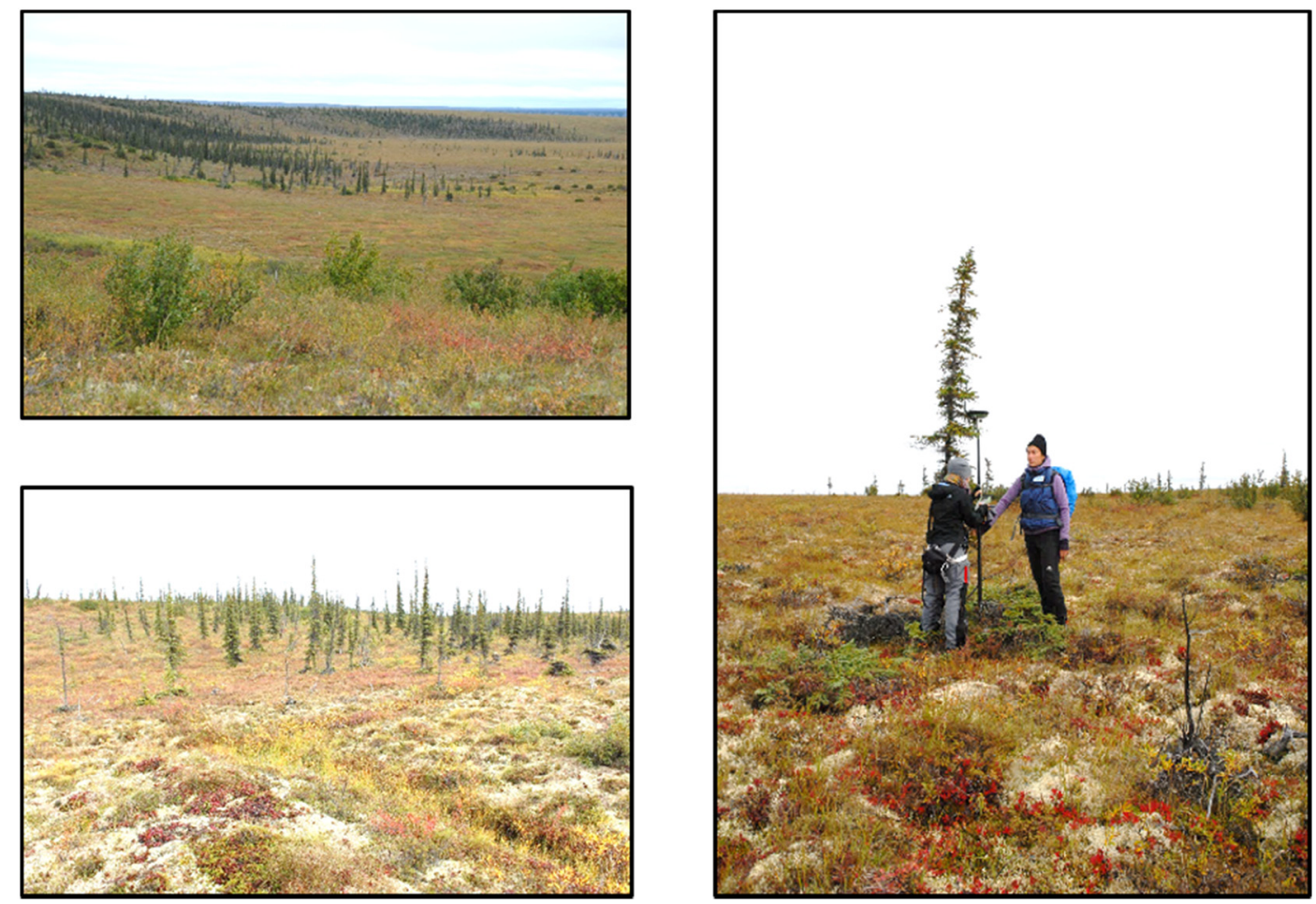

Fig. 2. Ground-based photos showing forest areas and the structure of a typical black spruce tree. Persons are for scale.

Table 1

General characteristics of the TanDEM-X dataset.

\begin{tabular}{ll}
\hline Relative orbit & 61 \\
Local time of acquisitions (UTC $-6 \mathrm{~h})$ & $20: 26$ \\
Path & Ascending \\
Looking direction & Right \\
Incidence angle & $45-47^{\circ}$ \\
Polarization & Single, VV \\
Slant range pixel spacing & $1.36 \mathrm{~m}$ \\
Azimuth pixel spacing & $2.04 \mathrm{~m}$ \\
\hline
\end{tabular}

Table 2

Characteristics of the TanDEM-X acquisitions and meteorological conditions. Temperature is given for 20:00 local time (station TRAIL VALLEY); precipitation is given as the daily total (station INUVIK CLIMATE). Date format is YYYYMMDD.

\begin{tabular}{lllll}
\hline Date & $\begin{array}{l}\text { Effective } \\
\text { baseline, } \mathrm{m}\end{array}$ & $\begin{array}{l}\text { Height of } \\
\text { ambiguity, } \mathrm{m}\end{array}$ & $\begin{array}{l}\text { Air } \\
\text { temperature, }{ }^{\circ} \mathrm{C}\end{array}$ & Precipitation, mm \\
\hline 20150601 & 584.147 & 14.164 & -2.7 & 3.0 \\
20150623 & 584.202 & 14.162 & 12.6 & 0.9 \\
20150715 & 584.392 & 14.157 & 15.2 & 0.0 \\
20150726 & 584.456 & 14.113 & 12.0 & 1.4 \\
20150806 & 583.836 & 14.128 & 4.2 & 8.4 \\
20150817 & 582.919 & 14.152 & 6.9 & 2.4 \\
20150828 & 583.844 & 14.126 & 4.9 & 0.5 \\
\hline
\end{tabular}

the resolution of multilooked TanDEM-X data.

Vegetation height was derived by subtracting the terrain elevation (i.e. DTM pixel values) from the non-ground points in the ALS point cloud. A raster of vegetation height was generated with a $1 \mathrm{~m}$ cell size by using the maximum vegetation height values per cell and then resampled to a cell size of $10 \mathrm{~m}$ to match the resolution of multilooked TanDEM-X data. The maximum value was chosen to include the response from the tallest trees. Finally, the vegetation height raster was smoothed with a low-pass filter, $3 \times 3$ pixels in size. Further details on the derivation of DTM and vegetation height can be found in Anders

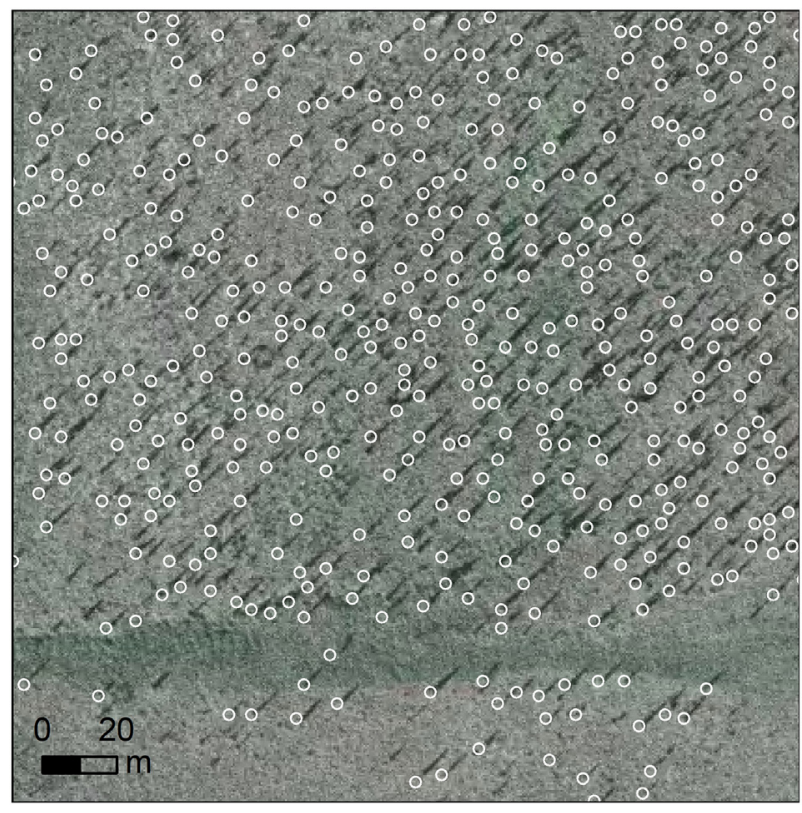

Fig. 3. ALS-detected single trees (white empty circles) on top of the high-resolution airborne orthophoto (C) Northwest Territories Centre for Geomatics). Trees can be identified on the orthophoto by their linear shadows.

et al. (2018).

Additionally, the position of individual trees was extracted from the $1 \mathrm{~m}$ cell size vegetation height raster based on local maxima within a search radius of $3 \mathrm{~m}$. A local maximum was considered a tree if its height was at least $1.5 \mathrm{~m}$. Using local maxima is a well-established method for the single tree detection (e.g. Hyyppä et al., 2001; Kaartinen et al., 2012) and is especially suitable for sparse forest as one in our study. The search radius of $3 \mathrm{~m}$ was chosen based on the typical minimum distance between the trees, which according to the field knowledge and visual analysis of open-access high-resolution $(0.5 \mathrm{~m})$ 


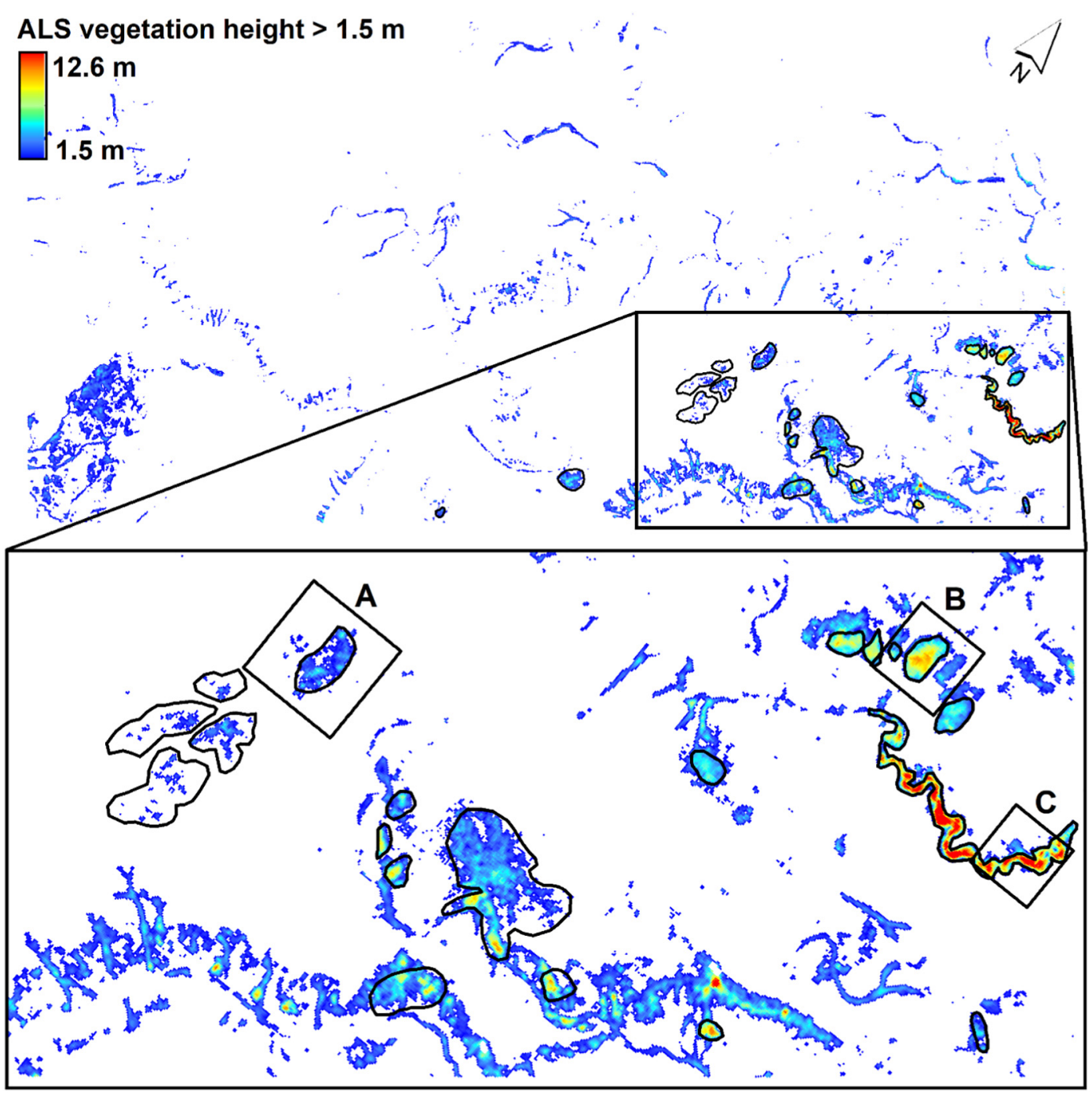

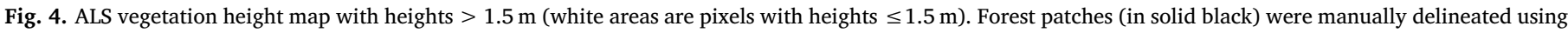
this map and orthophotos. Black lettered boxes A, B, and C locate forest patches which are enlarged in Fig. 5.

airborne orthophotos acquired in 2004-2008 (Northwest Territories Centre for Geomatics, http://www.geomatics.gov.nt.ca) is larger than $3 \mathrm{~m}$. Comparison between detected single trees and orthophotos confirms a reasonable performance of the method (Fig. 3). Furthermore, we manually removed some misidentified trees, e.g. tall shrubs.

Based on the position of single trees we derived a metric for the tree density as the number of trees per area, i.e. per $10 \times 10 \mathrm{~m}$ to match the resolution of TanDEM-X data. The number of trees per area is a meaningful representation of the tree density for our study area where trees have very narrow crown and trunk (see Fig. 2). To count the trees in a pixel in a continuous way, and, thus, to account for an arbitrary grid structure, we used a multivariate kernel density estimator with the maximum likelihood cross-validation method (Python module statsmodels). This method allows finding the optimal bandwidth (i.e. width of the kernel, also known as smoothing parameter) which is neither over-smoothing nor under-smoothing the data. The found optimal bandwidth was $12.7 \mathrm{~m}$ and $13.8 \mathrm{~m}$ in longitude and latitude directions respectively.

\subsection{TanDEM-X data processing}

The TanDEM-X data were processed using the Gamma radar software (Werner et al., 2000). SSC data were converted to Gamma Single Look Complex (SLC) format. We obtained three different metrics from the CoSSC pairs: (i) backscatter from the master image of each pair; (ii) InSAR height from each pair; (iii) bistatic coherence from each pair.

For backscatter derivation, SLC data were multi-looked by factors of 5 in range and azimuth directions, in order to obtain intensity values with reduced speckle and roughly squared pixels with a ground range size of 9.5 by $10.2 \mathrm{~m}$. Pixel-area correction was performed to account for terrain-induced variation of radar brightness (Small, 2011). Terrainbased normalization area was calculated using the ALS-based DTM.

In general, InSAR height (or scattering phase center height) is a result of subtracting a DTM, which represents the ground surface without elevated objects (e.g. Höfle and Rutzinger, 2011), from a SARderived Digital Surface Model (DSM). In our study, we used the ALSbased DTM to simulate the bare ground topography phase. For each TanDEM-X bistatic pair we obtained the differential interferogram by subtracting the simulated topography phase from the TanDEM-X InSAR phase. The differential interferograms were then smoothed using an adaptive filter based on the local fringe spectrum (Goldstein and Werner, 1998). The filtered interferograms were unwrapped using the minimal cost flow algorithm (Costantini, 1998), where zero-height value was assigned to a ground pixel with minimum vegetation. To avoid water bodies, a mask with coherence values $>0.5$ (mean coherence value for the water bodies) was used for the unwrapping. After that, the unwrapped phase was converted to the delta height in meters, which represents the InSAR height. 

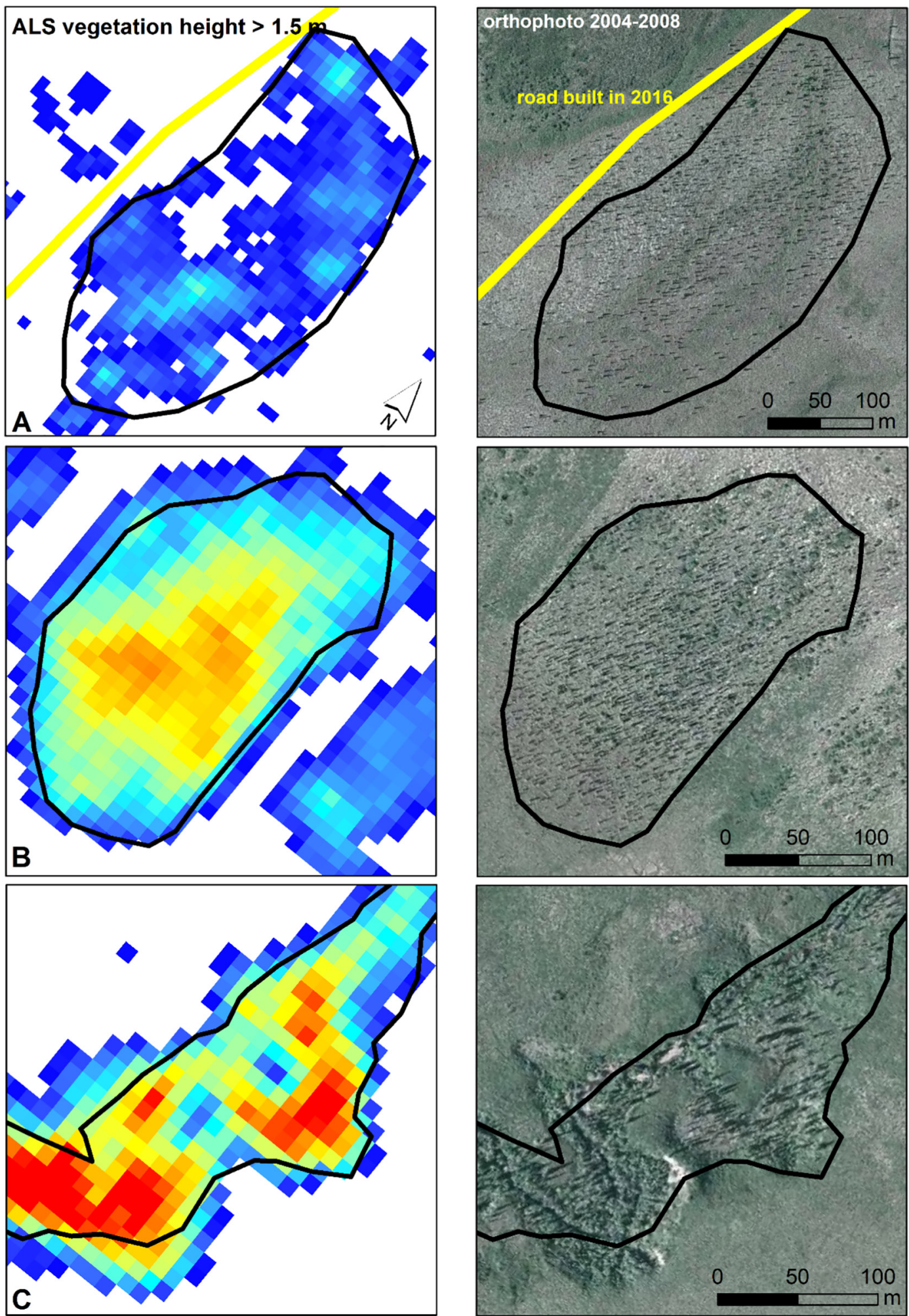

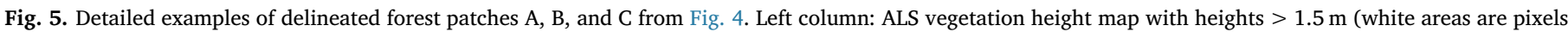
with heights $\leq 1.5 \mathrm{~m}$ ). Color scale is the same as in Fig. 4. Right column: high-resolution airborne orthophotos (C) Northwest Territories Centre for Geomatics).

To attribute the bistatic coherence to the volumetric component we assume that the other potential sources of decorrelation such as thermal and quantization noise, residual co-registration errors or range spectral mismatch are negligible for the TanDEM-X. Thermal noise is generally characterized by the signal-to-noise ratio which is typically high for the TanDEM-X system and increases after subsequent multilooking. Co-registration of the images within a CoSSC pair is precise with subpixel accuracy. The range spectral decorrelation was minimized by range spectral filtering, and residual decorrelation was deemed small due to the subdued topography and the moderate baseline length (compared to the critical baseline). Ambiguities, which can also contribute to decorrelation, were not apparent owing to the relatively uniform backscatter cross-sections. Bistatic coherence images were derived from corresponding differential interferograms and multilooked CoSSC 
Table 3

Main statistics of the ALS vegetation height and TanDEM-X metrics for the entire area covered by the ALS survey (Fig. 6).

\begin{tabular}{|c|c|c|c|c|c|c|c|}
\hline & Min & Max & Median & Mean & Standard deviation & p95 & p99 \\
\hline ALS vegetation height & $0.03 \mathrm{~m}$ & $12.6 \mathrm{~m}$ & $0.21 \mathrm{~m}$ & $0.42 \mathrm{~m}$ & $0.56 \mathrm{~m}$ & $1.46 \mathrm{~m}$ & $2.68 \mathrm{~m}$ \\
\hline TanDEM-X backscatter & $-22.24 \mathrm{~dB}$ & $-6.78 \mathrm{~dB}$ & $-12.62 \mathrm{~dB}$ & $-12.56 \mathrm{~dB}$ & $0.80 \mathrm{~dB}$ & $-11.17 \mathrm{~dB}$ & $-10.54 \mathrm{~dB}$ \\
\hline TanDEM-X coherence & 0.45 & 0.91 & 0.86 & 0.86 & 0.02 & 0.88 & 0.89 \\
\hline TanDEM-X InSAR height & $-0.97 \mathrm{~m}$ & $0.99 \mathrm{~m}$ & $-0.03 \mathrm{~m}$ & $-0.01 \mathrm{~m}$ & $0.13 \mathrm{~m}$ & $0.23 \mathrm{~m}$ & $0.43 \mathrm{~m}$ \\
\hline
\end{tabular}

intensity images with an estimation window of $5 \times 5$ pixels.

For both terrain-based normalization of backscatter and InSAR height calculation, a precise co-registration of the ALS-based DTM to the TanDEM-X pairs was needed. For the precise offsets calculation, we simulated an intensity image from the ALS-based DTM. We derived range and azimuth offsets using cross-correlation optimization of original and simulated SAR images. The algorithm calculates offset fields by correlating images in multiple windows across the scene. We calculated the registration polynomials from the offset fields, and applied them to correct the small shift between the ALS-based DTM and the TanDEM-X pairs.

Backscatter, InSAR height, and the coherence images were geocoded, using the ALS-based DTM, to the Universal Transverse Mercator (UTM) projection, zone $8 \mathrm{~N}$ WGS84, with a pixel size of $10 \mathrm{~m}$. Water bodies were clipped out from all maps. We combined all seven images of each TanDEM-X metric in three temporal stacks and derived a mean image for each of the stacks. Finally, the mean images were additionally smoothed with low-pass filter $3 \times 3$ pixels in size. Note that the geometry of the acquisitions, including the very stable baselines, was the same for all scenes, and, therefore, stacking of the images without any correction is justified. Hereinafter, backscatter, InSAR height, and coherence represent the temporal means of each metric.

\subsection{Delineation of forest patches}

We manually delineated 22 forest patches of different sizes using the ALS vegetation height map and the orthophotos. To do this, we removed all pixels with the heights of $<1.5 \mathrm{~m}$ from the ALS vegetation height map (Fig. 4). We visually checked the remaining groups of pixels against the orthophotos. If a group of pixels was identified as a forest patch on the orthophotos, we manually delineated this group. There were no strict criteria on where to draw the border of a forest patch but we aimed to delineate all groups with compactly growing trees and ignored standalone trees. Three detailed examples are shown in Fig. 5. Areas of the delineated forest patches varied from $0.005 \mathrm{~km}^{2}$ to $0.33 \mathrm{~km}^{2}$ and the total area of the combined patches was $1.3 \mathrm{~km}^{2}$. To make the forest sample as large as possible, we included even the smallest forest patches into the analysis. Most of the patches were situated on the hillslopes with the exception of one specific area with elongated shape which was situated along a stream channel (Fig. 5C).

We extracted the TanDEM-X metrics (backscatter, coherence, InSAR height) as well as ALS vegetation height and tree density within the delineated forest patches. We use simple linear regression to examine the relationship between all three TanDEM-X metrics and the ALS vegetation height within the combined area of all forest patches. Additionally, we estimated the effect of tree density on the relationship of TanDEM-X metrics to ALS vegetation height. In the end, we used random forests regression to build a prediction model for ALS vegetation height using all TanDEM-X metrics together.

\subsection{Pair consistency test and multitemporal stacking}

The looking geometry and the perpendicular baselines were almost identical for all the TanDEM-X pairs. Therefore, we expected the pairs to be highly correlated with each other, given similar environmental conditions at the time of acquisition. We compared all possible pairs of
TanDEM-X metrics within the combined forest patches to examine their consistency and whether the meteorological conditions had an effect on that consistency. There were two potentially influencing environmental events: freezing conditions during the acquisition on 1 June 2015 and precipitation on 6 August 2015. We also examined the effect of using the temporal mean compared to single images for all TanDEM-X metrics as they relate to the ALS vegetation height.

\section{Results}

\subsection{TanDEM-X metrics and ALS vegetation height}

First, we present a general overview of ALS vegetation height and TanDEM-X metrics (backscatter, coherence, and InSAR height) over the entire area covered by the ALS survey (Table 3). The area was generally characterized by low vegetation, with the median of $0.21 \mathrm{~m}$ and 99th percentile of $2.68 \mathrm{~m}$. The coherence was generally high with the median of 0.86 . Standard deviation of both coherence and backscatter was low: 0.02 and $0.8 \mathrm{~dB}$ correspondingly. The InSAR height varied between -1 and $1 \mathrm{~m}$. A negative InSAR height value could indicate two phenomena. First, it could indicate an increase of elevation between TanDEM-X (2015) and ALS (2016) acquisitions. Second, the TanDEM-X signal can penetrate to a slightly deeper layer than the ALS-based DTM, for instance, when over bare ground.

We examined visually the spatial patterns of the backscatter, coherence, and InSAR height and compared them with the ALS vegetation height, using orthophotographs as a reference (Fig. 6). In general, all three TanDEM-X metrics were sensitive to the tall vegetation in the stream channels, i.e. in the south eastern part of the area. Backscatter and InSAR height were high and coherence was low within these areas. A large shrub-covered zone in the western part of the area was well identified by both high backscatter and InSAR height but not by coherence. A road, built in 2016 (after the TanDEM-X acquisitions and during the ALS survey), is clearly visible as negative InSAR height. Over the entire area, covered by the ALS survey, ALS vegetation height correlated the most with InSAR height $(r=0.52)$, only moderately inversely correlated with coherence $(r=-0.4)$, and did not correlate with backscatter $(r=0.02)$.

We visually examined several parts of the study area with forest patches more closely (Fig. 7). According to the ALS vegetation height map, the tallest trees $(>10 \mathrm{~m})$ were within the forest patch along the stream channel in C. The backscatter was high over the forest patches in $\mathrm{B}$ and $\mathrm{C}$ but also over shrub covered areas such as a distinct shrub patch in A (left of the road), areas from both sides of the forest patch in B, and the area on the left side from the stream channel in C. Forest patches in general were not well distinguished by backscatter. In contrast, the coherence pattern mostly agreed with the border of delineated forest patches. Coherence was generally not sensitive to shrubs, with the exception of low coherence in the shrub-covered slopes at the stream channel in C. InSAR height was high over the forest patches and shrubs in all areas. A general overview of ALS vegetation height and TanDEM$\mathrm{X}$ metrics (backscatter, coherence, and InSAR height) over the combined area of all 22 delineated forest patches is given in Table 4 .

We examined the relationship between ALS vegetation height and all TanDEM-X metrics (backscatter, coherence, InSAR height), using the data points (pixels) from the combined area of all 22 delineated forest 

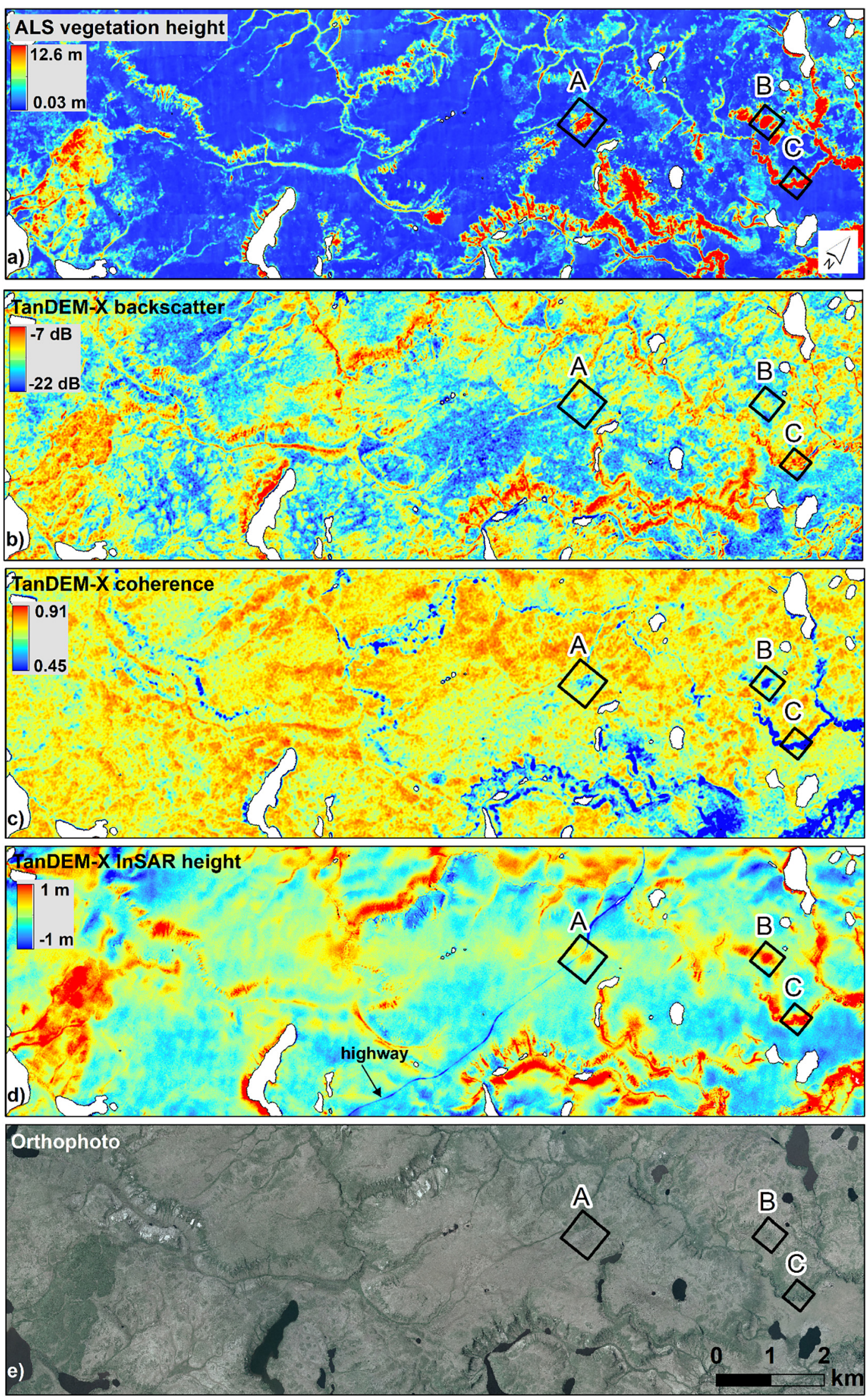

Fig. 6. Overview of the area covered by the ALS survey: a) ALS vegetation height; b) TanDEM-X backscatter; c) coherence; d) InSAR height; e) orthophoto (C Northwest Territories Centre for Geomatics). Zoom boxes in Fig. 7 are marked on all the maps as black rectangles. 

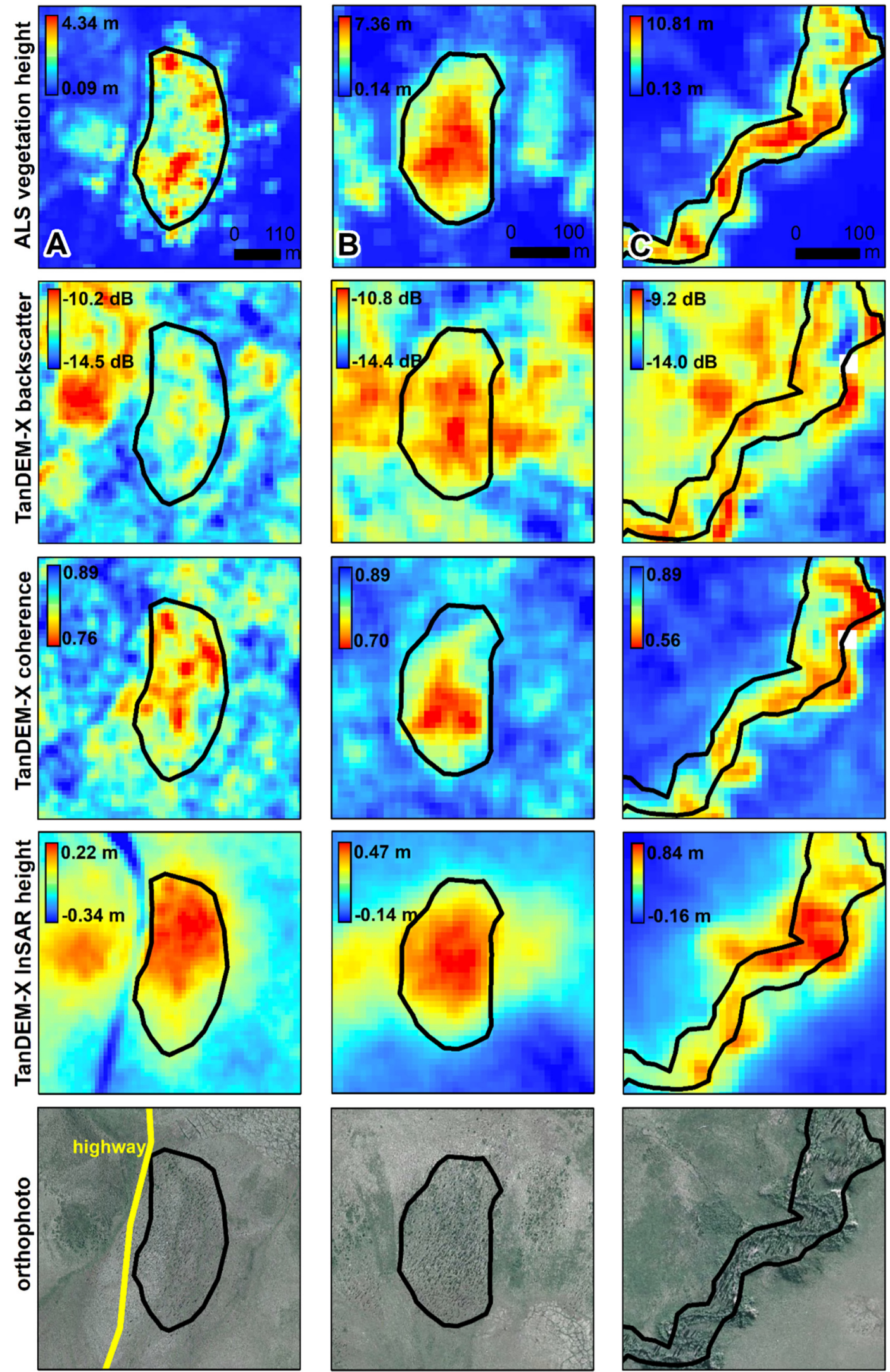

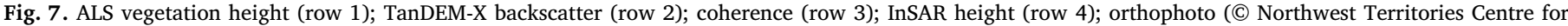

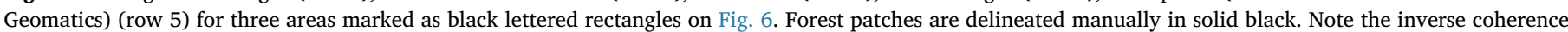
scale, enabling an easier visual comparison with the other metrics. Letters A, B, and C correspond to the boxes in Fig. 6 . 
Table 4

Main statistics of the ALS vegetation height and TanDEM-X metrics for the combined area of all 22 delineated forest patches.

\begin{tabular}{|c|c|c|c|c|c|c|c|}
\hline & Min & $\operatorname{Max}$ & Median & Mean & Standard deviation & p95 & p99 \\
\hline ALS vegetation height & $0.12 \mathrm{~m}$ & $12.58 \mathrm{~m}$ & $2.06 \mathrm{~m}$ & $2.47 \mathrm{~m}$ & $1.88 \mathrm{~m}$ & $6.33 \mathrm{~m}$ & $8.86 \mathrm{~m}$ \\
\hline TanDEM-X backscatter & $-14.33 \mathrm{~dB}$ & $-8.38 \mathrm{~dB}$ & $-12.78 \mathrm{~dB}$ & $-12.57 \mathrm{~dB}$ & $0.88 \mathrm{~dB}$ & $-10.8 \mathrm{~dB}$ & $-10.26 \mathrm{~dB}$ \\
\hline TanDEM-X coherence & 0.56 & 0.89 & 0.83 & 0.81 & 0.04 & 0.86 & 0.87 \\
\hline TanDEM-X InSAR height & $-0.16 \mathrm{~m}$ & $0.84 \mathrm{~m}$ & $0.05 \mathrm{~m}$ & $0.09 \mathrm{~m}$ & $0.15 \mathrm{~m}$ & $0.40 \mathrm{~m}$ & $0.64 \mathrm{~m}$ \\
\hline
\end{tabular}
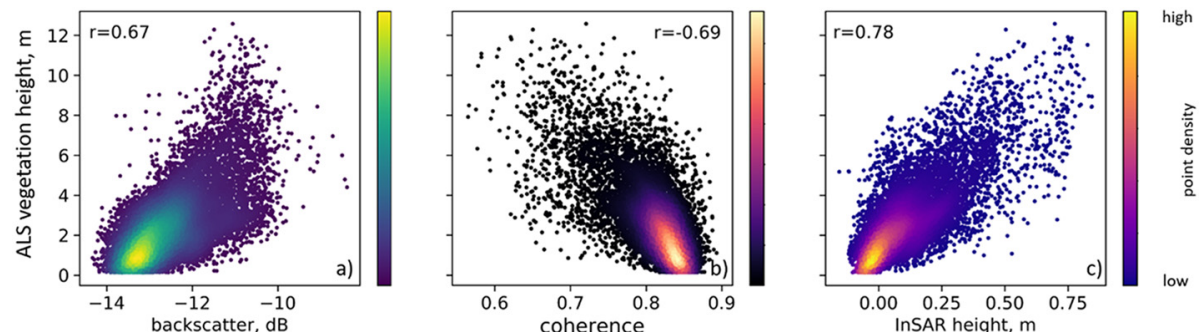

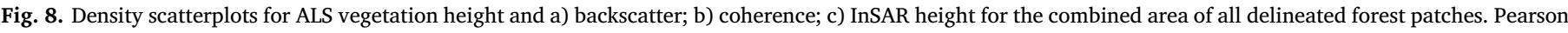
correlation coefficient is given for each plot. Data point density is shown as high and low for simplicity.
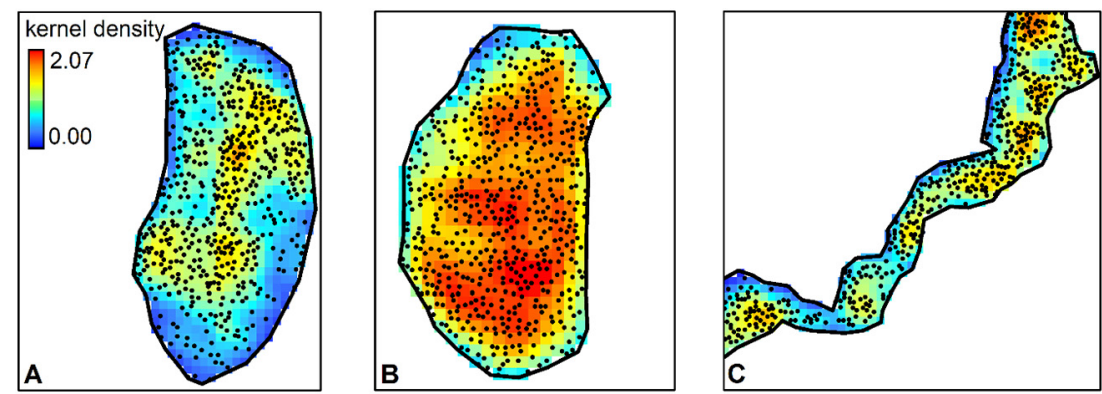

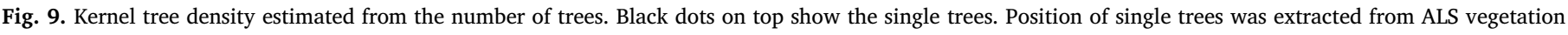
height map using local maxima.

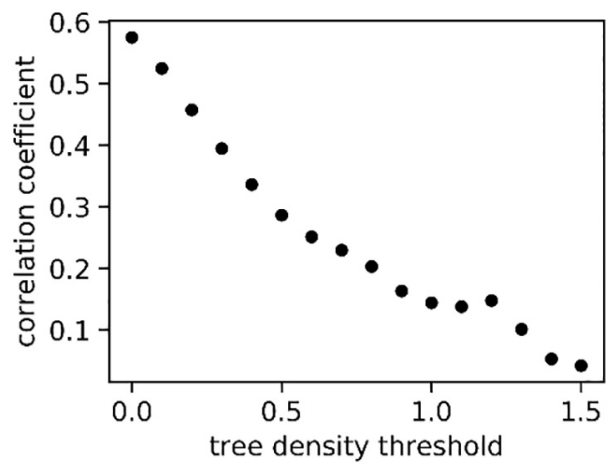

Fig. 10. Pearson correlation coefficient between the ALS vegetation height and tree density for tree density thresholds increasing from 0 to 1.5 with the step of 0.1 .

patches. All three TanDEM-X metrics show a strong linear relationship with the ALS height (Fig. 8). The Pearson correlation coefficient for the backscatter was $r=0.67$, for the coherence $r=-0.69$, and for the InSAR height $r=0.78$.

\subsection{TanDEM-X metrics and tree density}

We first present the result of kernel density estimated from the number of trees exemplarily for the same three forest patches A, B, and C (Fig. 9).

To detect whether there is a relationship between TanDEM-X metrics and the tree density, we first checked how the ALS vegetation height and the tree density are related. We found a strong linear relationship between these two parameters in the combined area of all forest patches with Pearson correlation coefficient of $r=0.58$. This strong relationship can be explained by the sparse nature of the studied forest and the inevitable inclusion of pixels or even groups of pixels without trees into the analysis. To eliminate this effect, we checked the correlation coefficient between the ALS vegetation height and the tree density for density threshold increasing from 0 to 1.5 with the step of 0.1 (Fig. 10). Number of included points ranged from 12,681 (density $>0$ ) to 877 (density $>1.5$ ). Correlation coefficient almost linearly decreased with the increase of the density threshold.

We chose the tree density $>1$ (number of points $=3630$ ) as a threshold at which the correlation between the tree height and density was below 0.15 , and examined the relationships between tree density and all TanDEM-X metrics only for the points with the tree density $>1$ (Fig. 11). All three TanDEM-X metrics show a very weak linear relationship with the kernel tree density. The Pearson correlation coefficient for the backscatter was $r=0.02$, for the coherence $r=-0.15$, and for the InSAR height $r=0.19$.

We also checked whether the relationship between the ALS vegetation height and TanDEM-X metrics depended on the tree density. Using natural breaks, we chose three density classes: low (0-0.52); medium (0.52-1.1); and high (1.1-2.07). For all density classes the relationships between the ALS vegetation height and all TanDEM-X metrics persisted their directions and remained strong (Fig. 12).

For the next step we combined the backscatter, coherence, and InSAR height to predict ALS vegetation height with the random forests regression. We used three sets of data: (i) all points from combined forest patches; (ii) points from combined forest patches with the 

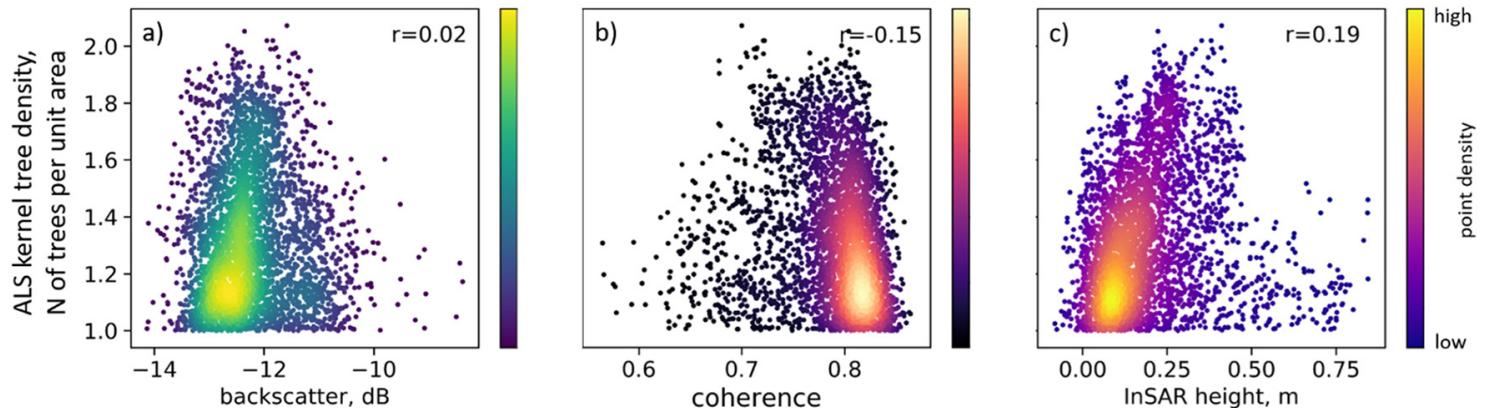

Fig. 11. Scatterplots for the ALS kernel tree density and a) backscatter; b) coherence; c) InSAR height for the combined area of all delineated forest patches with the tree density $>1$. Pearson correlation coefficient is given for each plot. Data point density is shown as high and low for simplicity.
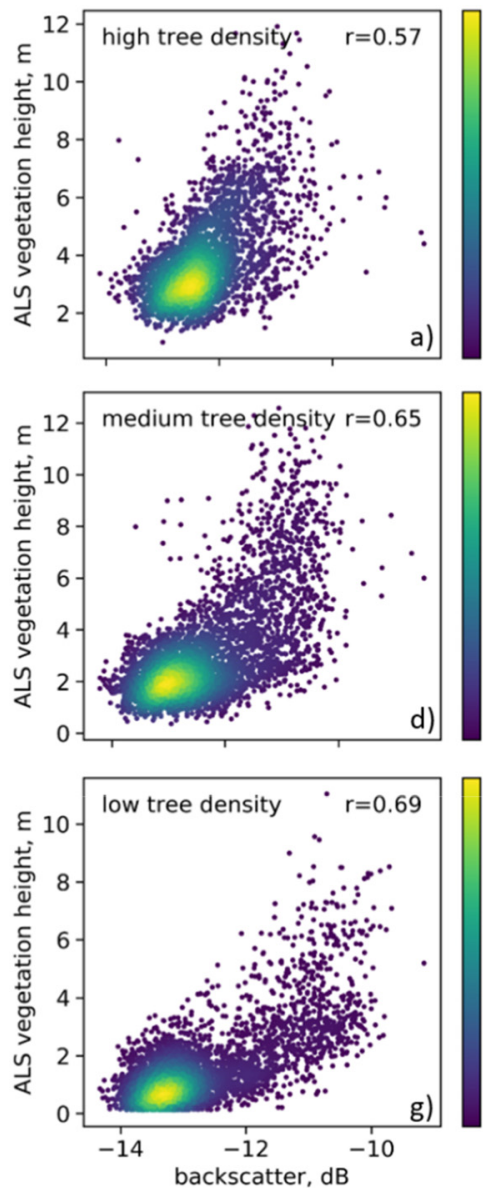
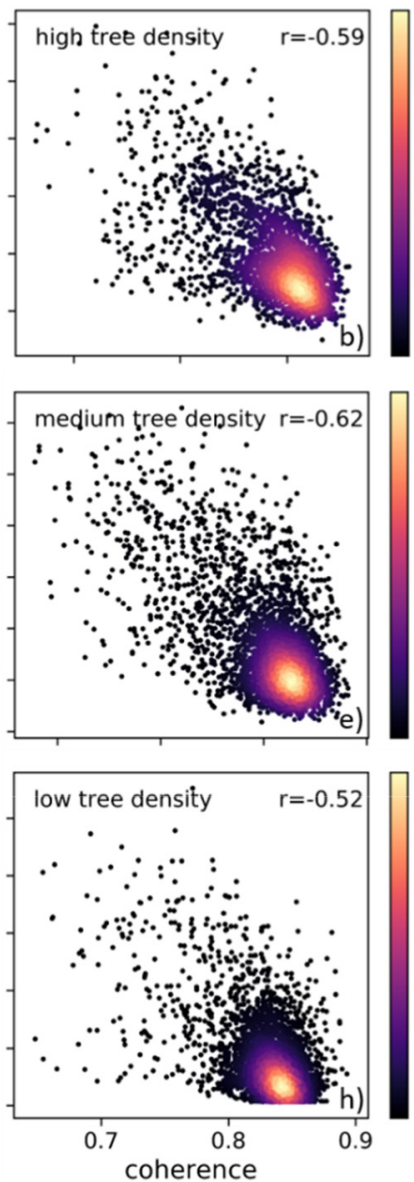
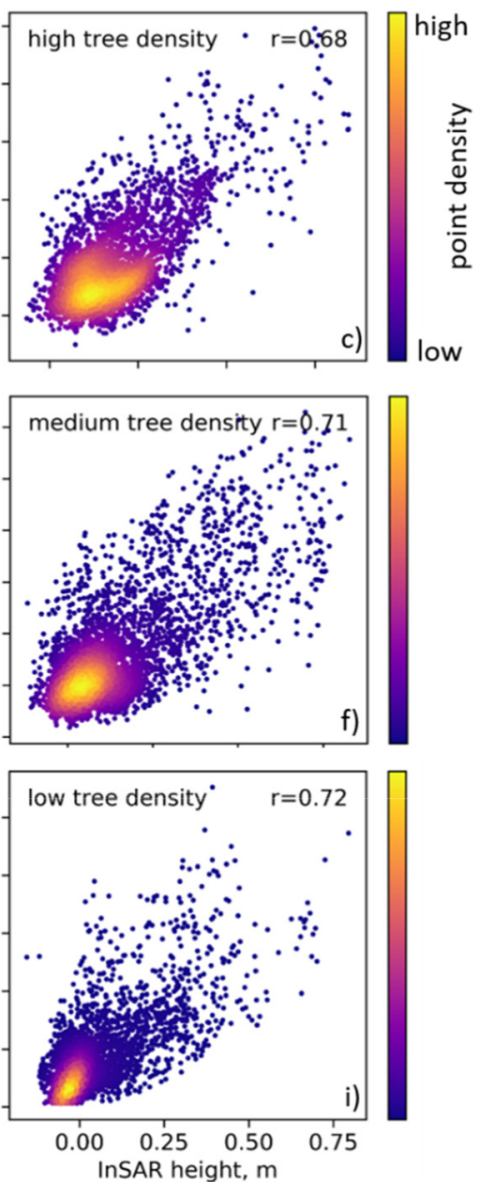

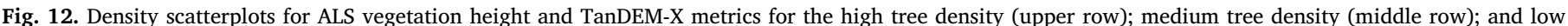
density (lower row) classes. Pearson correlation coefficient is given for each plot.

medium tree density; (iii) points from combined forest patches with high tree density. Number of "trees" in the random forest regression was set to 50 and the result did not significantly change with the increasing number of "trees". Regression "trees" were generated by drawing a replacement from two thirds of the data for training and onethird for testing for each tree. We ran the regression 20 times and took the average result for the presentation. For the data points from all forest patches, the relationship between the predicted and observed ALS vegetation height featured a relatively high coefficient of determination, $\mathrm{R}^{2}$ of 0.72 , a mean absolute error (MAE) of $0.72 \mathrm{~m}$, and an accuracy (which is defined as $100 \%$ - mean absolute percentage error) of 53.6\% (Fig. 13a). For the medium density dataset, the relationship featured a lower $\mathrm{R}^{2}$ of 0.66 , a slightly higher MAE of $0.78 \mathrm{~m}$, and an improved accuracy of $67.2 \%$ (Fig. 13b). For the high density dataset, the relationship featured $\mathrm{R}^{2}$ of 0.63 , MAE of $0.7 \mathrm{~m}$, and the best accuracy from three datasets of $79.8 \%$ (Fig. 13c).

In order to estimate the usefulness of the variables in the random forest we evaluated the importance of each predictor. The importance represents in percentages how much the prediction is improved by including a particular variable. The best predictor variable for all three datasets was the InSAR height, and the importance of the backscatter and coherence slightly increased for the datasets with both high and medium tree density (Table 5). 

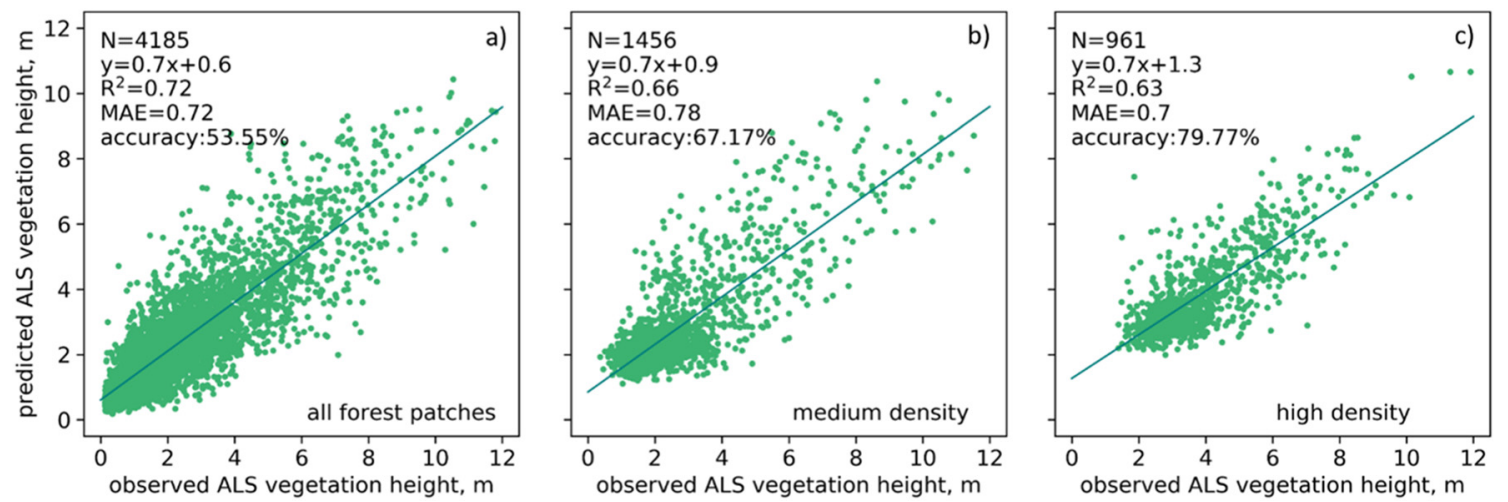

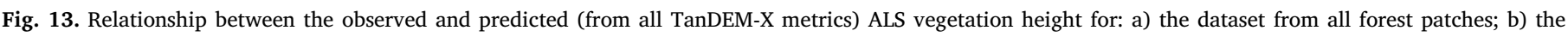
dataset from all forest patches with medium tree density; c) the dataset from all forest patches with high tree density. The solid line shows the best linear fit.

Table 5

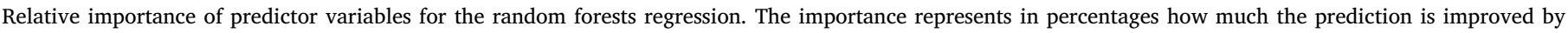
including a particular variable.

\begin{tabular}{|c|c|c|c|}
\hline TanDEM-X metric & Importance, $\%$ (all forest patches) & Importance, $\%$ (medium tree density) & Importance, $\%$ (high tree density) \\
\hline Backscatter & 14 & 20 & 20 \\
\hline Coherence & 16 & 20 & 19 \\
\hline InSAR height & 70 & 60 & 61 \\
\hline
\end{tabular}

\subsection{Consistency between the TanDEM-X pairs}

For the demonstrated results we used the multitemporal stack of the TanDEM-X pairs. To make sure that the temporal averaging of the TanDEM-X pairs was not affected by some anomalous pair, we investigated the consistency between all TanDEM-X pairs. Since the looking geometry and the baselines were the same for all the pairs, weather conditions could be the main influencing factor. We compared all possible pairs of TanDEM-X metrics within the area of combined forest patches and calculated the correlation coefficients. Correlation between backscatter pairs was generally high and varied between 0.62 and 0.77 with a mean of $0.7 \pm 0.04$ (Fig. 14). Generally, there was no systematic difference between backscatter pairs.

Correlation between coherence pairs was also high and varied between 0.58 and 0.77 with a mean of $0.7 \pm 0.05$ (Fig. 15). Generally, there was no systematic difference between coherence pairs.

Correlation between InSAR height pairs was the strongest of TanDEM-X metrics, and varied between 0.78 and 0.92 with a mean of $0.86 \pm 0.04$ (Fig. 16). Generally, there was no systematic difference in InSAR height between pairs.

For all metrics, two acquisitions with the most contrasting meteorological conditions (20150601 with the slightly negative air temperatures and 20150806 with the precipitation) yielded in the lowest correlation coefficients among all pairs: $r=0.62$ for the backscatter, $r=-0.58$ for the coherence, and $r=0.78$ for the InSAR height.

\subsection{Effect of multitemporal averaging}

We also examined for all TanDEM-X metrics whether using the temporal mean is more advantageous than using single images. Pearson correlation coefficients between TanDEM-X metrics and ALS vegetation height are given in Table 6 . The relationship was stronger for the mean backscatter ( $r=0.67$ ) compared to the single backscatter images where $\mathrm{r}$ varied between 0.55 and 0.61 . The relationship was in general slightly stronger for the mean coherence $(r=-0.69)$ compared to the single coherence images with the exception of the one coherence image from 20150828 for which the relationship was stronger than for the mean. The relationship was also slightly stronger for the mean InSAR height $(r=0.78)$ compared to all single backscatter images where $r$ varied between 0.66 and 0.75 .

\section{Discussion}

In our study we observed high correlation between ALS-derived tree height and all three TanDEM-X variables: backscatter $(r=0.67)$, bistatic coherence $(r=-0.69)$, and InSAR height $(r=0.78)$ obtained as multitemporal mean of seven TanDEM-X CoSSC pairs with the same geometry and baseline. The tree density showed almost no relationship to the TanDEM-X metrics. We distinguished three tree density classes and showed that the relationships between all TanDEM-X metrics and tree height within each density classes remained strong. Random forests regression using all three TanDEM-X metrics predicted the tree height with a mean absolute error of $0.7 \mathrm{~m}$ and the accuracy of $53 \%$. The contribution to the explained variation was the highest from the InSAR height $(70 \%)$ while backscatter and coherence contributed equally less (15\%).

Numerous studies related SAR backscatter to above-ground biomass and reported a quick saturation especially for the X-band (e.g. Woodhouse, 2005). We found a strong relationship between the TanDEM-X backscatter and the ALS vegetation height for the forested area $(r=0.67)$, which weakened with a denser class of forest. There were some signs of saturation at approximately $5 \mathrm{~m}$ of ALS vegetation height. We showed no influence of the tree density on the TanDEM-X backscatter in our study $(r=0.02)$. It is possible, however, that the tree density was in general too low to detect any influence of it on the backscatter. On the other hand, such sparse forest is typical for the northern edge of the treeline and, therefore, the insensitivity to tree density that we have found is a useful observation. The fact that for the entire area covered by the ALS survey, we found no correlation between backscatter and ALS vegetation height, indicates that trees likely serve as strong scatterers while the rest of the vegetation (e.g. dwarf and tall shrubs, lichens, and sedges) influences the backscatter through its density and roughness rather than the height.

We observed a strong inverse relationship between ALS vegetation height and TanDEM-X bistatic coherence $(r=-0.69)$ for the forested area. Assuming that no external DTM is needed to derive coherence, we suggest that this TanDEM-X metric can be very useful for the remote sensing of the treeline. Similar to backscatter, we found only very weak 

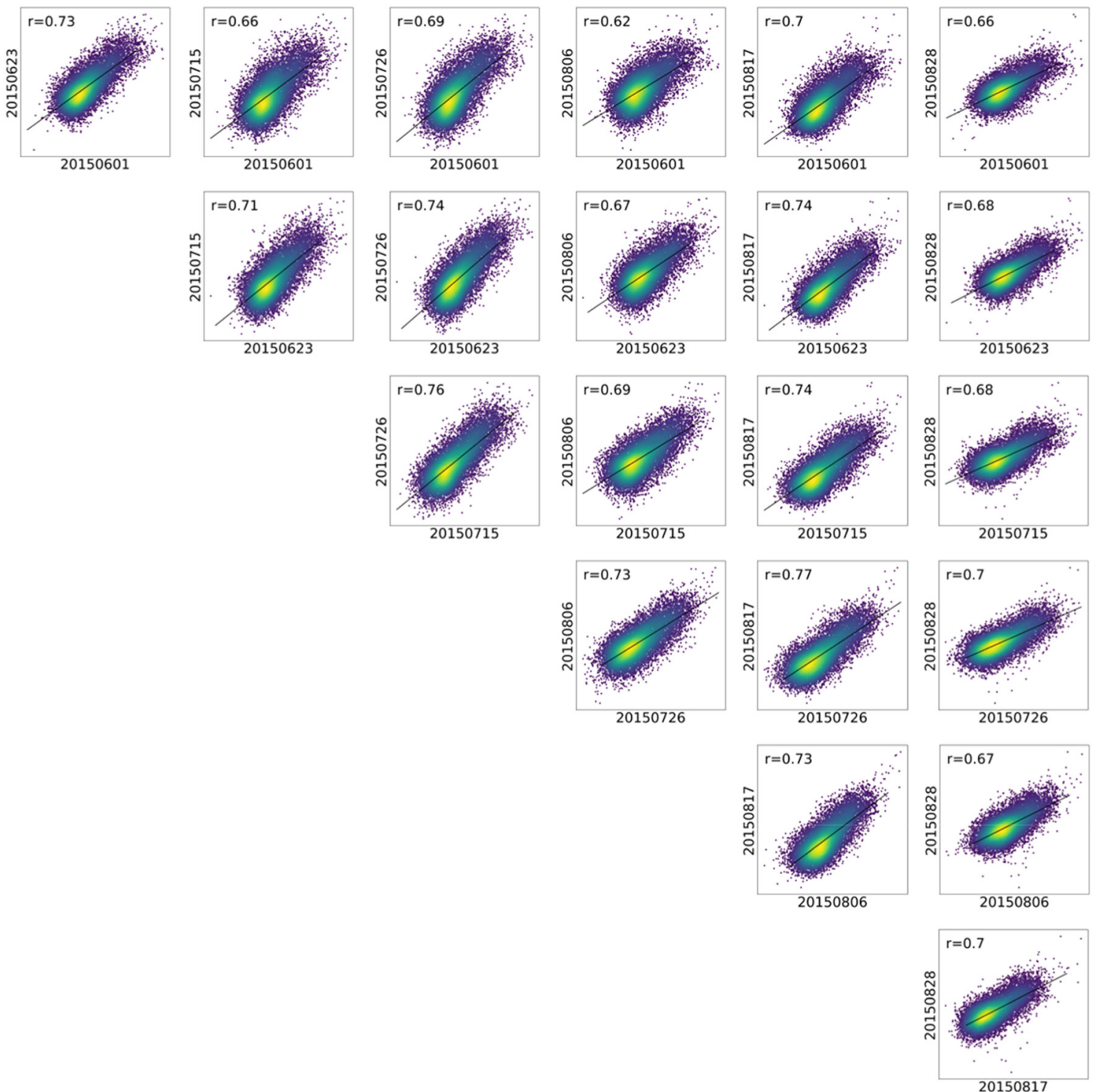

Fig. 14. Density scatterplots of TanDEM-X backscatter for all pair combinations. Pearson correlation coefficients are given for each plot. The one-to-one relationship is shown as a black line.

relationship between the tree density and the coherence $(r=-0.15)$, although the relationship was also inverse as for the height. Sadeghi et al. (2016) also did not find a relationship between tree density and TanDEM-X coherence in the Canadian boreal forest with higher density (13 stems per $100 \mathrm{~m}^{2}$ on average). For the entire area covered by the ALS survey, we found a rather moderate correlation between coherence and ALS vegetation height, which likely indicates that besides the height, other properties (i.e. density and coverage) of the typical tundra vegetation influence the coherence.

A number of previous studies have shown that InSAR height is strongly related to above-ground biomass and canopy height for forests with high biomass (e.g. Persson and Fransson, 2017; Solberg et al., 2017; Sadeghi et al., 2018). In our study we observed a strong relationship between InSAR height and ALS vegetation height $(r=0.78)$ for the forested area. We also found a rather strong correlation between InSAR height and ALS vegetation height $(r=0.52)$ for the entire area covered by the ALS survey - an expected observation, considering that the InSAR height is the most direct expression of the vegetation height among all TanDEM-X metrics. In general, InSAR height in our study was about one order of magnitude lower than ALS vegetation heights. This may indicate that the TanDEM-X signal is not able to accurately estimate the height of such sparse forest, but can capture well the spatial variations. Compared to the boreal or tropical forests, where the $\mathrm{X}$-band signal interacts with the upper few centimeters of dense canopy, in the sparse forests of the treeline zone, the SAR signal likely has a complex interaction between the ground and the tree elements which do not form a considerable canopy. Furthermore, the derivation of the InSAR height requires an independent, high-quality DTM, which often is not available, especially in high latitudes. This is a very substantial limitation.

Askne et al. (2013), Olesk et al. (2015), Soja et al. (2015), and Olesk et al. (2016) used Interferometric Water Cloud Model and its modifications as well as empirical (data-driven) relationships to estimate boreal forest biomass and height from TanDEM-X metrics. The former models generally consider the forest as a layer (or multiple layers) of volume scatterers located over the ground, with or without gaps in vegetation. Some studies suggest that using simple regression models is often preferable due to the many simplifications and assumptions required for physical models, or that multipolarization SAR data should be used. Our data-driven model for forest height estimation implicitly accounted for the unique structural properties of very sparse forest with trees featuring very narrow trunks and crown. Such forest configuration 


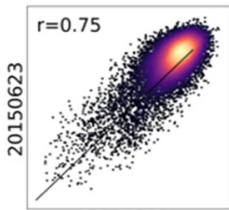

20150601
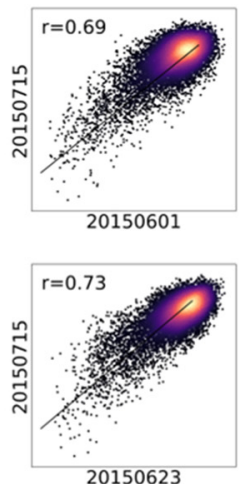

20150623

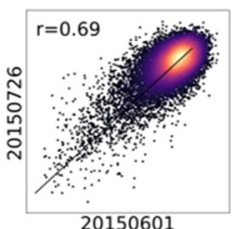

20150601
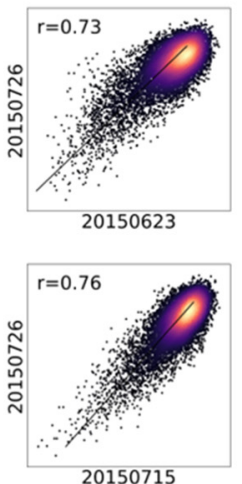

20150715

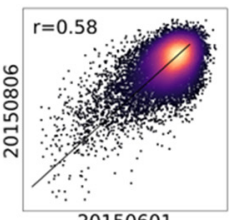

20150601

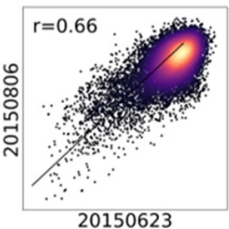

20150623

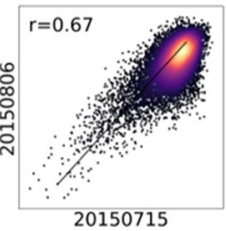

20150715
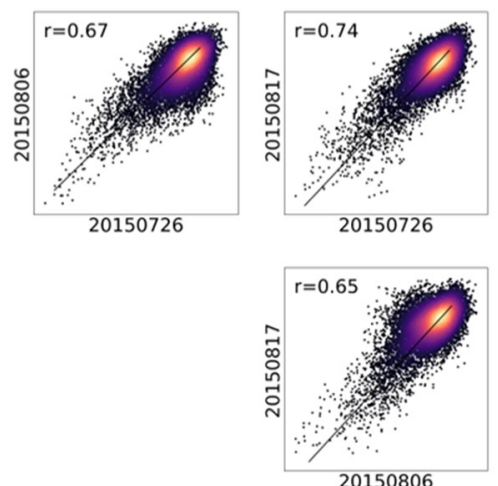

20150806

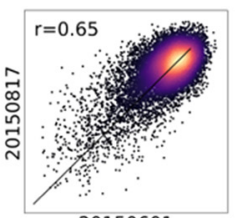

20150601
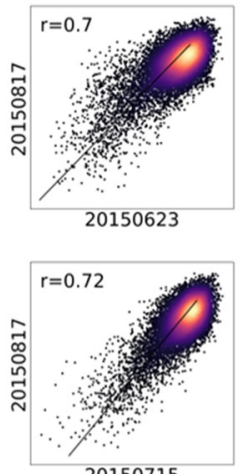

20150715
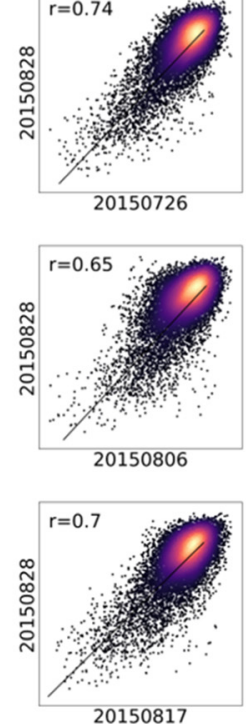

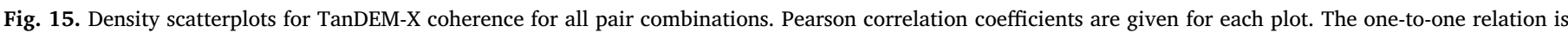
shown as a black line.

is difficult to capture in estimation algorithms based on scattering models. In our study we used three metrics from single-polarization TanDEM-X data (backscatter, coherence, InSAR height) in a random forests regression model. Our data show a strong relationship between reference and predicted forest height over the full range of heights. We reached an $R^{2}$ of 0.7 and a MAE of $0.7 \mathrm{~m}$ which is better than, for instance, in Karila et al. (2015), where the $\mathrm{R}^{2}$ between predicted and observed forest height based on the TanDEM-X InSAR height and coherence, varied between 0.34 and 0.57 for different acquisition dates.

Current global land-cover maps are not able to resolve forest patches of the size we observed in our study. We delineated the forest patches manually using high-resolution orthophotos together with the ALS vegetation height map to have a better control over the sample. We acknowledge that it was necessary to identify the forest areas prior to estimating the tree height with the TanDEM-X metrics. With respect to potential automated mapping, the TanDEM-X coherence demonstrated the best sensitivity to the forest areas but still could not fully discriminate them from some shrubby areas (Fig. 7). We did not aim at achieving automated mapping of the forest patches in this study and leave this accomplishment for future studies. Martone et al. (2018) developed a global forest/non-forest (FNF) map at a ground pixel spacing of $50 \mathrm{~m} \times 50 \mathrm{~m}$, based on TanDEM-X data acquired for global DEM formation. None of our forest patches were identified as forest in their FNF map indicating that likely the FNF map is not usable at the northern edge of the treeline where the forest patches are very small, but probably can be used in the more southern areas.

In our analysis, we were limited to the area, covered by the ALS survey, which included forest patches, similar in shape and located mostly on gentle hillslopes. One elongated forest area, situated along a stream channel, was, however, different in shape and in the positions on the landscape (Figs. 4 and 5). We checked the correlation between TanDEM-X variables and ALS vegetation height for this specific area. The correlation was strong for the coherence $(r=-0.73)$, and the InSAR height $(r=0.57)$ but rather low for the backscatter $(r=0.28)$ which can be related to the remaining shadow/layover effects influencing this topographically complicated area, or to the tall shrubs interacting with the backscatter signal. Therefore, we suggest using backscatter cautiously over such areas, and that the further research should be pursued in order to include a larger variety of spatial configurations of the forest patches or other forms of tree growth at the 

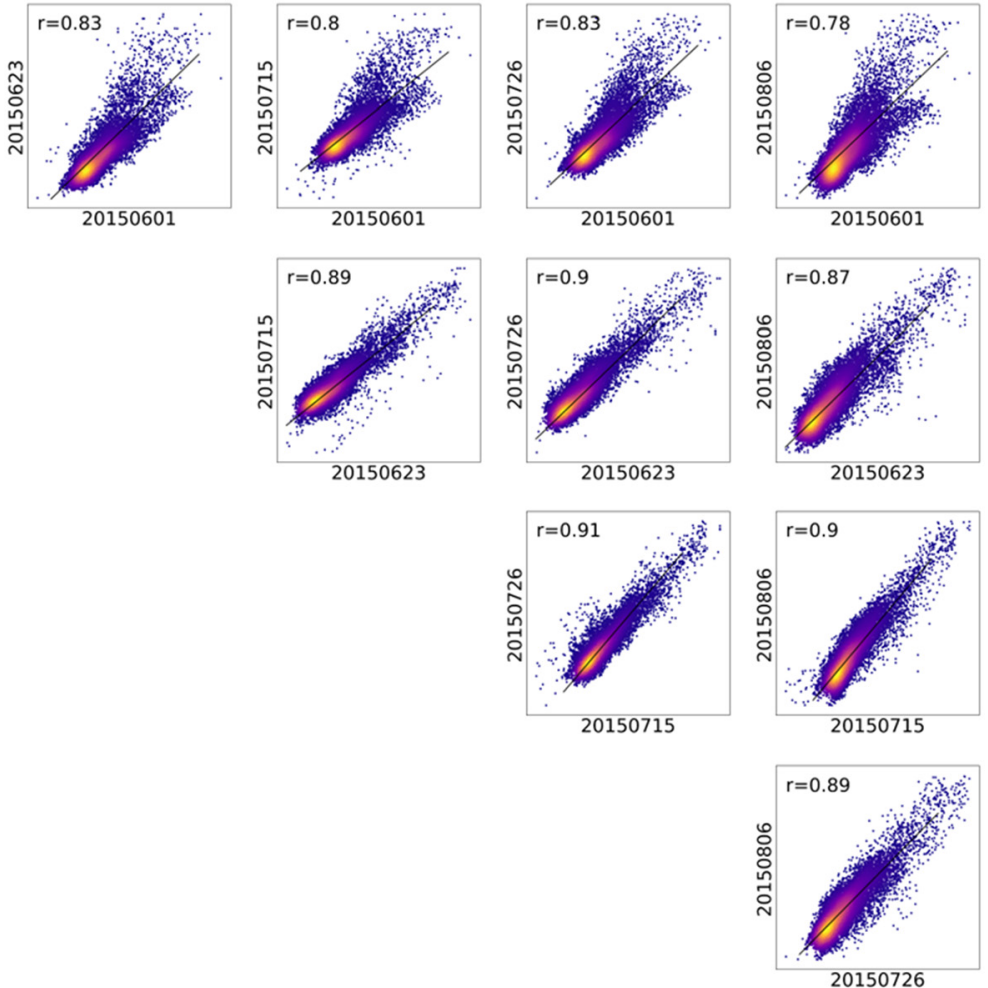
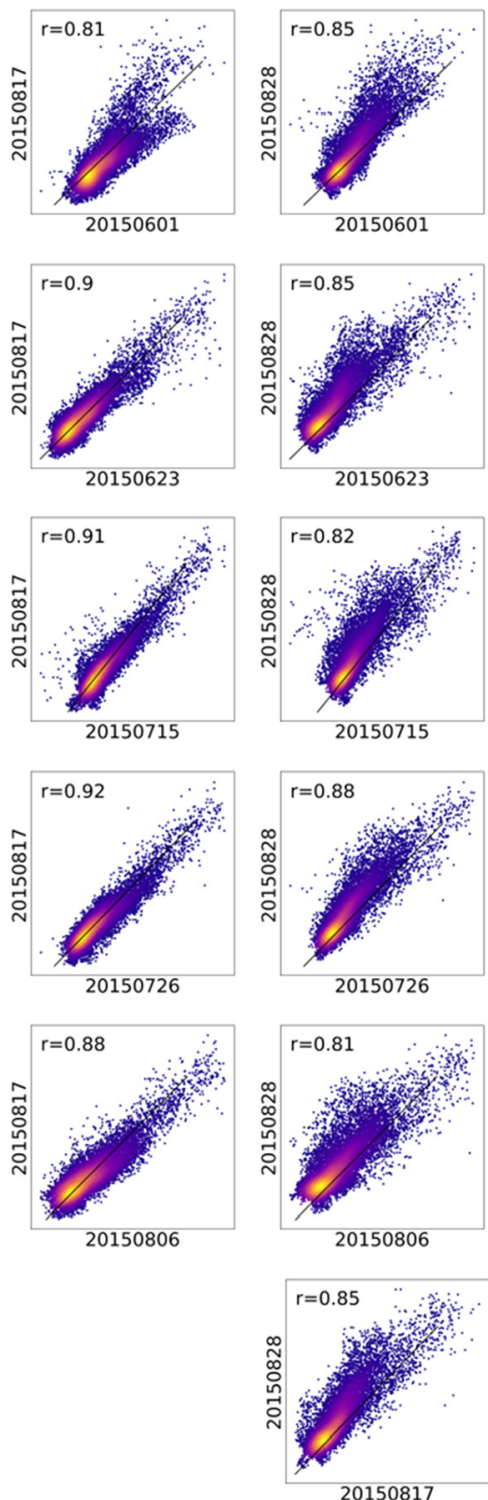

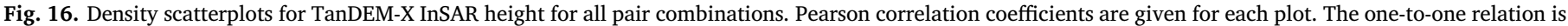
shown as a black line.

Table 6

Pearson correlation coefficients between TanDEM-X metrics and ALS vegetation height for all single acquisitions as well as for the temporal mean of acquisitions.

\begin{tabular}{llll}
\hline Date of TanDEM-X pair & r backscatter & r coherence & r InSAR height \\
\hline 20150601 & 0.57 & -0.65 & 0.66 \\
20150623 & 0.55 & -0.66 & 0.75 \\
20150715 & 0.58 & -0.66 & 0.73 \\
20150726 & 0.57 & -0.61 & 0.75 \\
20150806 & 0.6 & -0.55 & 0.73 \\
20150817 & 0.61 & -0.58 & 0.74 \\
20150828 & 0.56 & -0.74 & 0.74 \\
Temporal mean & 0.67 & -0.69 & 0.78
\end{tabular}

northern edge of the treeline.

In our study, the temporal stability between acquisitions was high for the backscatter (mean $r=0.7$ ). This is in line with the findings of Askne et al. (2017) who report a very high consistency between multiple TanDEM-X backscatter images over boreal forest, with the exception of acquisitions with high snow cover and precipitation. The temporal stability of the coherence was also high (mean $\mathrm{r}=0.7$ ). Askne et al. (2017) report a strong inconsistency between coherence pairs, especially for scenes with snow cover. In general, their coherence values varied between 0.25 and 0.94 (compared to our study with a range from 0.58 to 0.77 ), indicating much stronger volumetric decorrelation in the canopy of the boreal forest, and potentially higher temporal instability. The temporal stability of the InSAR height was the highest of all metrics (mean $r=0.86$ ). The environmental conditions (freezing and precipitation) possibly contributed to the lowest consistency between two acquisitions taken under these contrasting settings. Nevertheless, the consistency for this pair was still rather high for all TanDEM-X metrics, indicating that the analysis of the TanDEM-X data acquired under relatively mild meteorological conditions should not be a problem. We also showed that in most cases the temporal mean of TanDEM-X metrics yielded a stronger relationship with the ALS vegetation height, when compared to the performance of the single acquisitions. In general, however, the performance of the single acquisitions was comparable with the performance of the temporal mean, indicating that a single acquisition can also be used when multiple pairs are not available. 


\section{Conclusions}

This is the first study to explore the potential of TanDEM-X data for estimating tree height in small forest patches at the northern edge of the treeline zone in the Canadian Arctic. We tested the relationships between the ALS-derived forest height and SAR backscatter, bistatic coherence, and InSAR height from several TanDEM-X bistatic pairs of the same geometry and baseline. The linear regression yielded correlation coefficients of $0.57,-0.65$, and 0.69 for the backscatter, bistatic coherence, and InSAR height correspondingly. The tree density derived from ALS was low ( $\leq 2$ trees per ca. $175 \mathrm{~m}^{2}$ ) and showed almost no relationship to the TanDEM-X metrics, meaning that very likely these metrics can be solely attributed to the forest height in these environments. All three TanDEM-X metrics were then used as predictive variables for estimating the forest height with the random forests regression. Mean absolute error was $0.7 \mathrm{~m}$, which represents $30 \%$ of the mean forest height $(2.5 \mathrm{~m})$ in the study area. Using only bistatic coherence would lead to a larger error, but can be valuable when the external DTM, necessary for the formation of InSAR height, is not available. InSAR height strongly correlated to the ALS vegetation height but the absolute values differed by one order of magnitude. It is evident that the TanDEM-X metrics behave differently in the sparse forest of the transition zone than in dense forests. More studies from other sites in the vicinity of the treeline as well as TanDEM-X acquisitions with other geometries and baselines should provide more insights into the SAR signal interaction with a sparse and low forest. Assuming the global availability of the TanDEM-X bistatic data, acquired for the global DEM production, we suggest that a circum-polar assessment of the tree height in the forest-tundra transition zone can be pursued.

\section{Acknowledgments}

This work was core funded by the Federal Ministry for Economic Affairs and Energy (BMWi) and the German Aerospace Center (DLR), Germany, in the framework of the project PermaSAR (FKZ: 50EE1418). We thank Sina Muster, Inge Grünberg, and Stefan Kruse for the critical reading of the manuscript and the valuable comments.

\section{References}

Anders, K., Antonova, S., Boike, J., Gehrmann, M., Hartmann, J., Helm, V., Höfle, B., Marsh, P., Marx, S., Sachs, T., 2018. Airborne Laser Scanning (ALS) point clouds of Trail Valley Creek, NWT, Canada (2016). PANGAEA. https://doi.org/10.1594/ PANGAEA.894884.

Askne, J.I., Fransson, J.E., Santoro, M., Soja, M.J., Ulander, L.M., 2013. Model-based biomass estimation of a hemi-boreal forest from multitemporal TanDEM-X acquisitions. Remote Sens. 5 (11), 5574-5597.

Askne, J.I., Soja, M.J., Ulander, L.M., 2017. Biomass estimation in a boreal forest from TanDEM-X data, lidar DTM, and the interferometric water cloud model. Remote Sens. Environ. 196, 265-278.

Brown, J., Ferrians Jr., O.J., Heginbottom, J.A., Melnikov, E.S., 1998. Circum-Arctic Map of Permafrost and Ground Ice Conditions. National Snow and Ice Data Center/World Data Center for Glaciology, Boulder, CO revised February 2001. (Digital media).

Burn, C.R., Kokelj, S.V., 2009. The environment and permafrost of the Mackenzie Delta area. Permafr. Periglac. Process. 20 (2), 83-105.

Callaghan, T.V., Björn, L.O., Chapin III, F.S., Chernov, Y., Christensen, T.R., Huntley, B., ... Chaver, G., 2005. Arctic tundra and polar desert ecosystems. Arctic Climate Impact Assessment 1, 243-352.

Chapin III, F.S., Sturm, M., Serreze, M.C., McFadden, J.P., Key, J.R., Lloyd, A.H., Welker, J.M., 2005. Role of land-surface changes in Arctic summer warming. Science 310 (5748), 657-660. https://doi.org/10.1126/science.1117368.

Costantini, M., 1998. A novel phase unwrapping method based on network programming. IEEE Trans. Geosci. Remote Sens. 36, 813-821.

Environment and Climate Change Canada, 2019. Historical Data, Weather and Climate Hazards. http://climate.weather.gc.ca/historical_data/search historic data_e.html (accessed May 2019)

Frost, G.V., Epstein, H.E., 2014. Tall shrub and tree expansion in Siberian tundra ecotones since the 1960s. Glob. Chang. Biol. 20 (4), 1264-1277. https://doi.org/10.1111/gcb. 12406.

Goldstein, R.M., Werner, C.L., 1998. Radar interferogram filtering for geophysical applications. Geophys. Res. Lett. 25 (21), 4035-4038.

Hajnsek, I., Busche, T., Krieger, G., Zink, M., Schulze, D., Moreira, A., 2014. TanDEM-X Ground Segment Announcement of Opportunity: TanDEM-X Science Phase. German
Aerospace Center, Microwaves and Radar Institute, Germany, pp. 27 TD-PD-PL-0032, 19.05. 2014.

Harsch, M.A., Hulme, P.E., McGlone, M.S., Duncan, R.P., 2009. Are treelines advancing? A global meta-analysis of treeline response to climate warming. Ecol. Lett. 12 (10), 1040-1049.

Höfle, B., Rutzinger, M., 2011. Topographic airborne LiDAR in geomorphology: a technological perspective. Z. Geomorphol. Suppl. 55 (2), 1-29.

Hyyppä, J., Schardt, M., Haggrén, H., Koch, B., Lohr, U., Scherrer, H.U., ... Pyysalo, U., 2001. HIGH-SCAN: the first European-wide attempt to derive single-tree information from laserscanner data. The Photogrammetric Journal of Finland 17 (2), 58-68.

Kaartinen, H., Hyyppä, J., Yu, X., Vastaranta, M., Hyyppä, H., Kukko, A., ... Næsset, E., 2012. An international comparison of individual tree detection and extraction using airborne laser scanning. Remote Sens. 4 (4), 950-974.

Karila, K., Vastaranta, M., Karjalainen, M., Kaasalainen, S., 2015. TanDEM-X interferometry in the prediction of forest inventory attributes in managed boreal forests. Remote Sens. Environ. 159, 259-268.

Krieger, G., Moreira, A., Fiedler, H., Hajnsek, I., Werner, M., Younis, M., Zink, M., 2007. TanDEM-X: a satellite formation for high-resolution SAR interferometry. IEEE Trans. Geosci. Remote Sens. 45 (11), 3317-3341.

Lantz, T.C., Gergel, S.E., Henry, G.H., 2010. Response of green alder (Alnus viridis subsp. fruticosa) patch dynamics and plant community composition to fire and regional temperature in north-western Canada. J. Biogeogr. 37 (8), 1597-1610.

Lawrence, D.M., Koven, C.D., Swenson, S.C., Riley, W.J., Slater, A.G., 2015. Permafrost thaw and resulting soil moisture changes regulate projected high-latitude $\mathrm{CO} 2$ and CH4 emissions. Environ. Res. Lett. 10 (9), 094011.

Lenoir, J., Svenning, J.C., 2015. Climate-related range shifts - a global multidimensional synthesis and new research directions. Ecography 38 (1), 15-28.

MacDonald, G.M., Edwards, T.W.D., Moser, K.A., Pienitz, R., Smol, J.P., 1993. Rapid response of treeline, vegetation and lakes to past climate warming. Nature 361 , 243-246.

Marsh, P., Onclin, C., Neumann, N., 2002. Water and energy fluxes in the lower Mackenzie Valley, 1994/95. Atmosphere-Ocean 40 (2), 245-256.

Marsh, P., Bartlett, P., MacKay, M., Pohl, S., Lantz, T., 2010. Snowmelt energetics at a shrub tundra site in the western Canadian Arctic. Hydrol. Process. 24 (25), 3603-3620.

Martone, M., Rizzoli, P., Wecklich, C., González, C., Bueso-Bello, J.L., Valdo, P., Moreira, A., 2018. The global forest/non-forest map from TanDEM-X interferometric SAR data. Remote Sens. Environ. 205, 352-373. https://doi.org/10.1016/j.rse.2017.12.002.

Mathisen, I.E., Mikheeva, A., Tutubalina, O.V., Aune, S., Hofgaard, A., 2014. Fifty years of tree line change in the Khibiny Mountains, Russia: advantages of combined remote sensing and dendroecological approaches. Appl. Veg. Sci. 17 (1), 6-16.

Montesano, P.M., Nelson, R., Sun, G., Margolis, H., Kerber, A., Ranson, K.J., 2009. MODIS tree cover validation for the circumpolar taiga-tundra transition zone. Remote Sens. Environ. 113 (10), 2130-2141.

Montesano, P.M., Sun, G., Dubayah, R.O., Ranson, K.J., 2016. Spaceborne potential for examining taiga-tundra ecotone form and vulnerability. Biogeosciences 13 (13) 3847-3861.

Mücke, W., Briese, C., Hollaus, M., 2010. Terrain echo probability assignment based on full-waveform airborne laser scanning observables. In: Proceedings of ISPRS TC VII Symposium - 100 Years ISPRS, Vienna, Austria, pp. 157-162.

Olesk, A., Voormansik, K., Vain, A., Noorma, M., Praks, J., 2015. Seasonal differences in forest height estimation from interferometric TanDEM-X coherence data. IEEE Journal of Selected Topics in Applied Earth Observations and Remote Sensing 8 (12), 5565-5572.

Olesk, A., Praks, J., Antropov, O., Zalite, K., Arumäe, T., Voormansik, K., 2016. Interferometric SAR coherence models for characterization of hemiboreal forests using TanDEM-X data. Remote Sens. 8 (9), 700.

Persson, H., Olsson, H., Soja, M., Ulander, L., Fransson, J., 2017. Experiences from largescale forest mapping of Sweden using TanDEM-X data. Remote Sens. 9 (12), 1253.

Persson, H.J., Fransson, J.E., 2017. Comparison between TanDEM-X-and ALS-based estimation of aboveground biomass and tree height in boreal forests. Scand. J. For. Res. 32 (4), 306-319.

Pfeifer, N., Mandlburger, G., 2008. Filtering and DTM generation. In: Shan, J., Toth, C. (Eds.), Topographic Laser Ranging and Scanning: Principles and Processing. CRC Press, 9781420051421, pp. 307-333 2008, (invited).

Ranson, K.J., Sun, G., Kharuk, V.I., Kovacs, K., 2004. Assessing tundra-taiga boundary with multi-sensor satellite data. Remote Sens. Environ. 93 (3), 283-295.

Ranson, K.J., Montesano, P.M., Nelson, R., 2011. Object-based mapping of the circumpolar taiga-tundra ecotone with MODIS tree cover. Remote Sens. Environ. 115 (12), 3670-3680

Sadeghi, Y., St-Onge, B., Leblon, B., Simard, M., 2016. Canopy height model (CHM) derived from a TanDEM-X InSAR DSM and an airborne LiDAR DTM in boreal forest. IEEE Journal of Selected Topics in Applied Earth Observations and Remote Sensing 9 (1), 381-397.

Sadeghi, Y., St-Onge, B., Leblon, B., Prieur, J.F., Simard, M., 2018. Mapping boreal forest biomass from a SRTM and TanDEM-X based on canopy height model and Landsat spectral indices. Int. J. Appl. Earth Obs. Geoinf. 68, 202-213. https://doi.org/10. 1016/j.jag.2017.12.004.

Santoro, M., Cartus, O., 2018. Research pathways of forest above-ground biomass estimation based on SAR backscatter and interferometric SAR observations. Remote Sens. 10 (4), 608. https://doi.org/10.3390/rs10040608.

Schlund, M., von Poncet, F., Kuntz, S., Boehm, H.D.V., Hoekman, D.H., Schmullius, C., 2016. TanDEM-X elevation model data for canopy height and aboveground biomass retrieval in a tropical peat swamp forest. Int. J. Remote Sens. 37 (21), 5021-5044.

Serreze, M.C., Walsh, J.E., Chapin, F.S., Osterkamp, T., Dyurgerov, M., Romanovsky, V., Barry, R.G., 2000. Observational evidence of recent change in the northern high- 
latitude environment. Clim. Chang. 46 (1-2), 159-207.

Small, D., 2011. Flattening gamma: radiometric terrain correction for SAR imagery. IEEE Trans. Geosci. Remote Sens. 49 (8), 3081-3093.

Soja, M.J., Persson, H.J., Ulander, L.M., 2015. Estimation of forest biomass from two-level model inversion of single-pass InSAR data. IEEE Trans. Geosci. Remote Sens. 53 (9), 5083-5099.

Solberg, S., Astrup, R., Breidenbach, J., Nilsen, B., Weydahl, D., 2013. Monitoring spruce volume and biomass with InSAR data from TanDEM-X. Remote Sens. Environ. 139, $60-67$.

Solberg, S., Hansen, E.H., Gobakken, T., Naessset, E., Zahabu, E., 2017. Biomass and InSAR height relationship in a dense tropical forest. Remote Sens. Environ. 192, 166-175.

Thiel, C., Schmullius, C., 2016. The potential of ALOS PALSAR backscatter and InSAR coherence for forest growing stock volume estimation in Central Siberia. Remote Sens. Environ. 173, 258-273.

Treuhaft, R., Gonçalves, F., dos Santos, J.R., Keller, M., Palace, M., Madsen, S.N., ... Graça, P.M., 2015. Tropical-forest biomass estimation at X-band from the spaceborne TanDEM-X interferometer. IEEE Geosci. Remote Sens. Lett. 12 (2), 239-243.

Werner, C., Wegmüller, U., Strozzi, T., Wiesmann, A., 2000. Gamma SAR and interferometric processing software. In: Proceedings of the ERS-Envisat Symposium, Gothenburg, Sweden. vol. 1620. pp. 1620.

Wieczorek, M., Kruse, S., Epp, L.S., Kolmogorov, A., Nikolaev, A.N., Heinrich, I., Jeltsch, F., Pestryakova, L.A., Zibulski, R., Herzschuh, U., 2017. Dissimilar responses of larch stands in northern Siberia to increasing temperatures-a field and simulation based study. Ecology 98 (9), 2343-2355. https://doi.org/10.1002/ecy.1887.

Woodhouse, I.H., 2005. Introduction to Microwave Remote Sensing. CRC press. 